Aus der Poliklinik für Präventive Zahnmedizin, Parodontologie und Kariologie (Prof. Dr. med. dent. A Wiegand)

Im Zentrum Zahn-, Mund- und Kieferheilkunde

der Medizinischen Fakultät der Universität Göttingen

\title{
Effektivität schall- und ultraschallaktivierter Wurzelkanalspültechniken zur Entfernung von Debris aus dem Isthmus unterer \\ Molaren
}

Eine Mikro-CT-Studie

\author{
INAUGURAL-DISSERTATION \\ zur Erlangung des Doktorgrades \\ für Zahnmedizin \\ der Medizinischen Fakultät der \\ Georg-August-Universität zu Göttingen
}

vorgelegt von

Carolina Dèsirèe Koberg

aus

Minden

Göttingen 2019 
Dekan: Prof. Dr. med. W. Brück

\section{Betreuungsausschuss}

Betreuer/in:

Prof. Dr. Tina Rödig

Ko-Betreuer/in:

Prof. Dr. Matthias Rödiger

\section{Prüfungskommission}

Referent/in:

Prof. Dr. Tina Rödig

Ko-Referent/in:

Prof. Dr. Matthias Rödiger

Drittreferent/in:

Prof. Dr. Rainer Mausberg

Datum der mündlichen Prüfung: 16.03.2020 
Hiermit erkläre ich, die Dissertation mit dem Titel "Effektivität schall- und ultraschallaktivierter Wurzelkanalspültechniken zur Entfernung von Debris aus dem Isthmus unterer Molaren - Eine Mirko-CTStudie" eigenständig angefertigt und keine anderen als die von mir angegebenen Quellen und Hilfsmittel verwendet zu haben.

Göttingen, den 
Die vorliegende Promotionsschrift war die Grundlage für folgende Veröffentlichung:

Rödig T, Koberg C, Baxter S, Konietschke F, Wiegand A, Rizk M (2019):

Micro-CT evaluation of sonically and ultrasonically activated irrigation on the removal of hard-tissue debris from isthmus-containing mesial root canal systems of mandibular molars. Int Endod J 52, 1173-1181 


\section{Inhaltsverzeichnis}

Abbildungsverzeichnis ...........................................................................

Tabellenverzeichnis ................................................................................... IV

Abkürzungsverzeichnis ............................................................................. IV

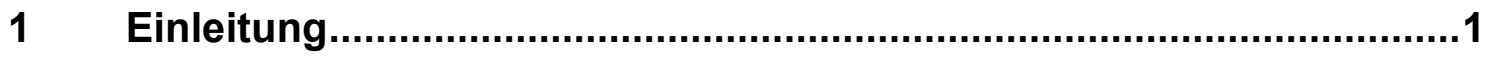

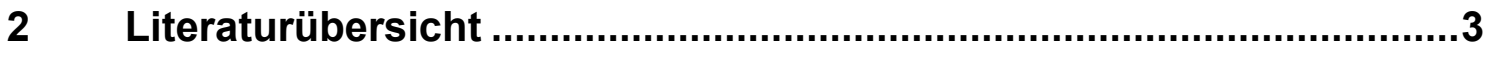

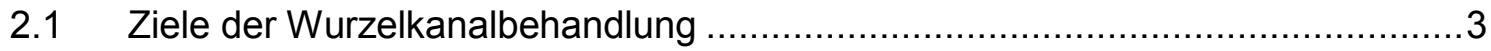

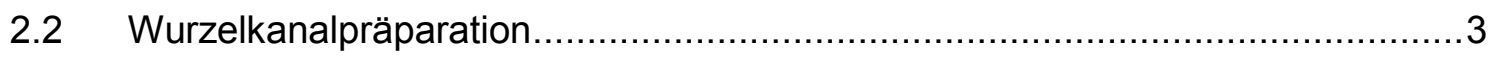

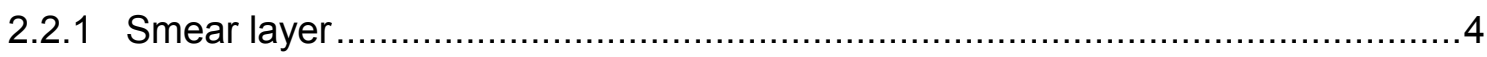

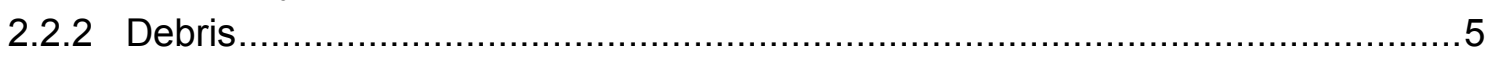

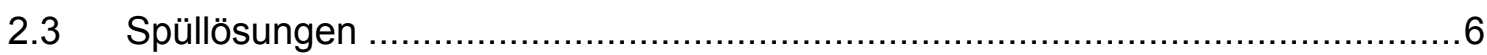

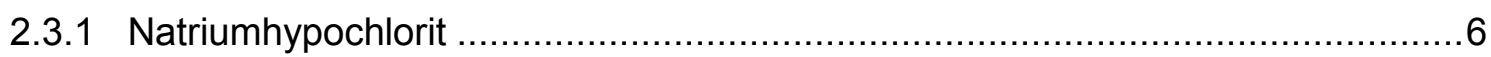

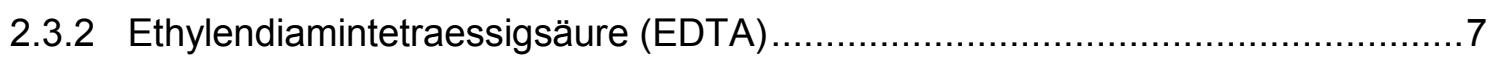

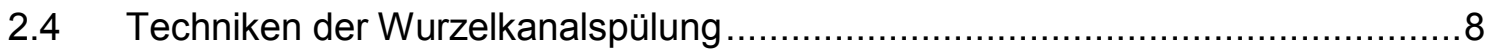

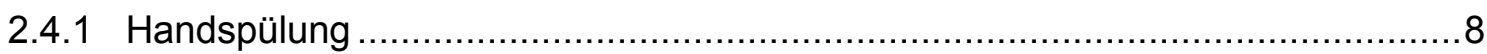

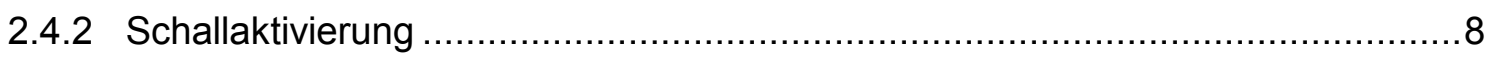

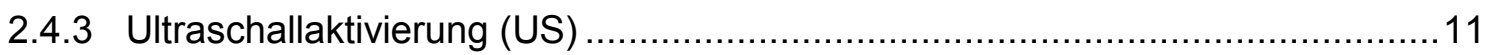

2.5 Evaluierung und Darstellung des Debris....................................................13

2.5.1 Die Mikro-Computertomografie..............................................................

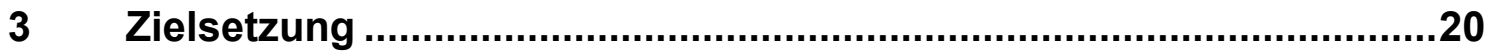

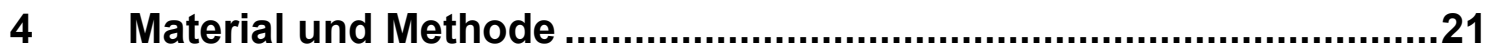

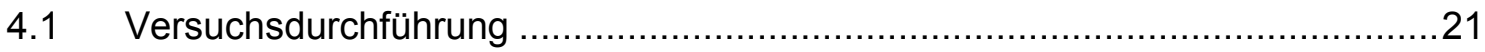

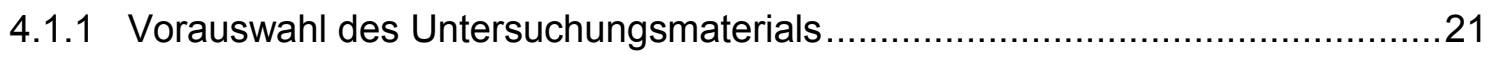

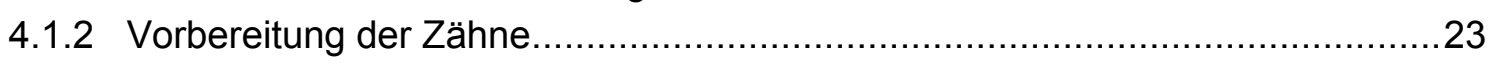

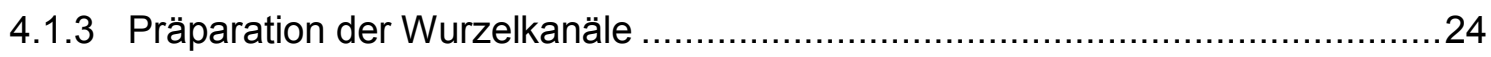

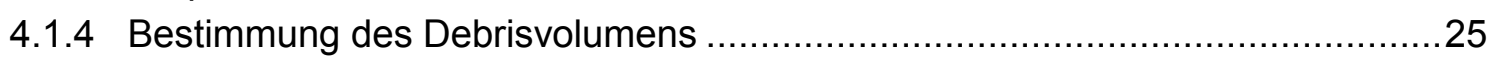

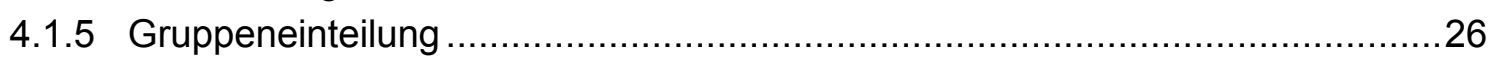

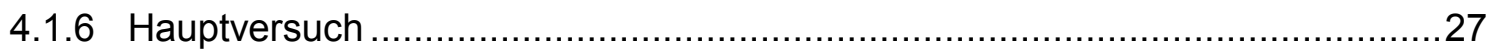

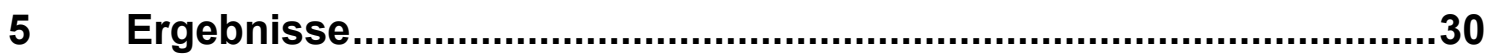

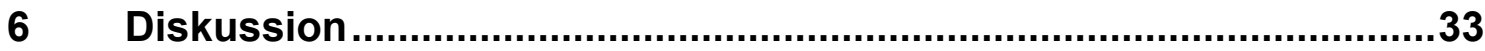

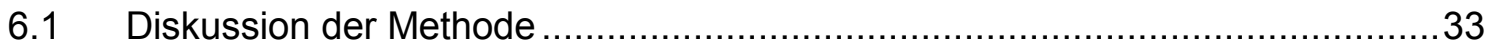

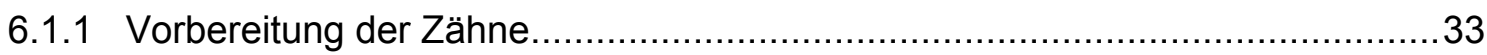

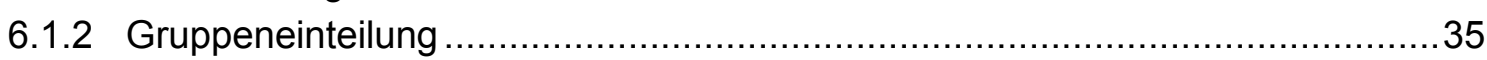

6.1.3 Evaluierung und Auswertung des Debris ......................................................

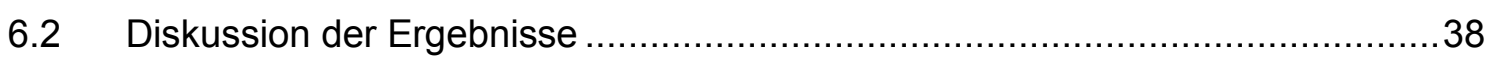

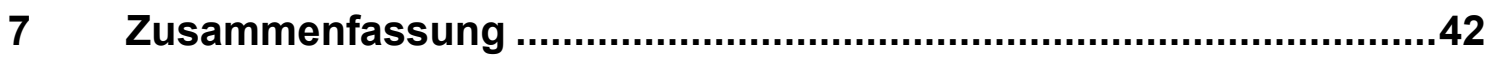




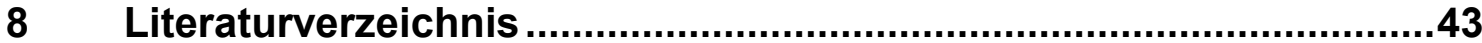

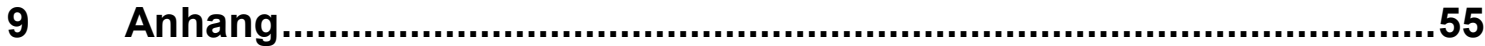

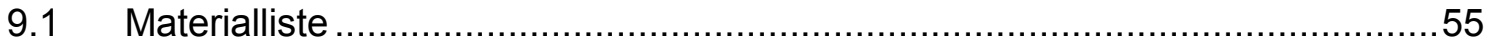




\section{Abbildungsverzeichnis}

Abbildung 1: Schallaktivierbarer Polyamid-Aufsatz EDDY ......................................

Abbildung 2: EndoActivator, EndoActivator-Aufsatz der Größe 15/.02 ......................10

Abbildung 3: Ultraschallaufsatz IRRI S der Größe 25 .............................................11

Abbildung 4: Schematische Darstellung eines Mikro-CT. ....................................... 14

Abbildung 5: Mikro-CT-Darstellung eines mesialen Wurzelkanalsystems....................16

Abbildung 6: Ringartefakte vor und nach der Korrektur ....................................... 17

Abbildung 7: Post-alignment-Einstellung. ......................................................... 18

Abbildung 8: Wurzelquerschnitt im CTAnalyzer vor und nach Durchführung des

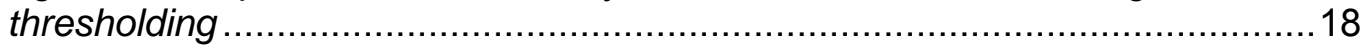

Abbildung 9: Mikro-CT-Abbildung eines rekonstruierten Wurzelkanalsystems mithilfe der Software CTVox................................................................ 19

Abbildung 10: Digitales Röntgenbild in bukko-lingualer Richtung inklusive Markierungen für die Bestimmung der Wurzelkanalkrümmung .....................21

Abbildung 11: Mikro-CT-Aufnahme einer mesialen Wurzel eines unteren Molaren mit dem Verlauf des mesio-bukkalen und mesio-lingualen Wurzelkanals entsprechend der Vertucci-Klasse II (mesio-distale Projektionsrichtung). ........22

Abbildung 12: Mesiale Wurzel mit apikalem Klebeverschluss und Kompositwand zur Aufnahme der Spülflüssigkeit.

Abbildung 13: Micro-CT-Bildsequenzanalyse eines präoperativen Zahnes im axialen Schnitt und Durchführung des thresholding ...

Abbildung 14: Mikro-CT-Bildsequenzen: Präoperativer Scan vor und nach Binarisierung. Postoperativer Scan mit Debrisansammlung im Isthmus vor

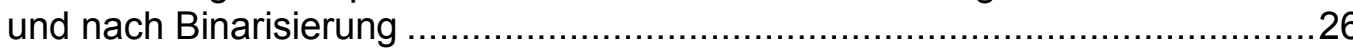

Abbildung 15: Spülprotokoll der experimentellen Gruppen ...................................27

Abbildung 16: Box-Plot-Diagramm zur Darstellung der Verteilung vom prozentualen Anteil der Reduzierung von Debris

Abbildung 17: Mesiale Ansicht repräsentativer 3D-Rekonstruktionen des Kanalsystems von vier Unterkiefer-Molaren vor und nach Präparation mit dem Reciproc-System und nach Abschlussspülprotokoll 


\section{Tabellenverzeichnis}

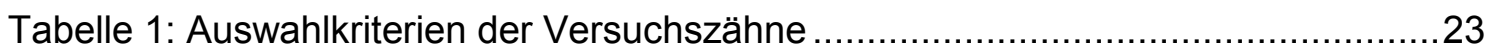

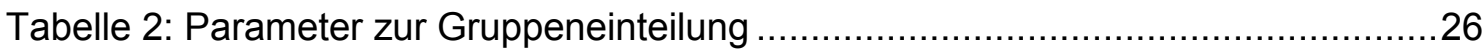

Tabelle 3: Isthmusbreiten der Proben unterteilt in die einzelnen Gruppen ....................30

Tabelle 4: Mittelwerte der einzelnen Gruppe ..................................................... 31 


\section{Abkürzungsverzeichnis}

$\begin{array}{ll}\text { AL } & \text { Arbeitslänge } \\ \text { ANOVA } & \text { analysis of variance; Varianzanalyse } \\ \text { CT } & \text { Computertomografie } \\ \text { EA } & \text { EndoActivator } \\ \text { ED } & \text { EDDY } \\ \text { EDTA } & \text { Ethylendiamintetraessigsäure } \\ \text { HD } & \text { Handspülung } \\ \text { ISO } & \text { Internationale Organisation für Normung } \\ \text { Mikro-CT } & \text { Mikro-Computertomografie } \\ \text { NaOCl } & \text { Natriumhypochlorit } \\ \text { NiTi } & \text { Nickel-Titan } \\ \text { PNG } & \text { portable network graphics } \\ \text { ROI } & \text { region of interest } \\ \text { US } & \text { Ultraschallaktivierung }\end{array}$




\section{$1 \quad$ Einleitung}

Bei Zähnen, die durch eine tiefe kariöse Läsion mit Beteiligung der Pulpa geschädigt wurden, bietet eine Wurzelkanalbehandlung eine adäquate Therapieoption, um den Zahn langfristig zu erhalten (SBU 2012). Der Erfolg einer Wurzelkanalbehandlung ist von der Eliminierung bzw. Reduktion von Bakterien und deren Toxinen im Kanalsystem abhängig (Versiani et al. 2016). Diese Mikroorganismen gelangen bei einer Dentinkaries und bei einer ParoEndo-Läsion über die Dentintubili zur Pulpa und rufen dort eine reversible Entzündung (Pulpitis) hervor (Larsen und Fiehn 2017). Wenn diese kariöse Läsion unbehandelt bleibt, breitet sich die Entzündung weiter im Pulpagewebe aus, und es entsteht eine irreversible Pulpitis mit anschließender Pulpanekrose. Die infizierte nekrotische Pulpa verursacht schließlich über das Foramen apicale eine Entzündung des periapikalen Gewebes (Parodontitis apicalis) (Taschieri et al. 2014). Die Ausheilung des periapikalen Gewebes gelingt nur durch Reduzierung der Mikroorganismen und ist somit ein wichtiges Ziel jeder Wurzelkanalbehandlung (Gründling et al. 2011). Der Erfolg einer endodontischen Behandlung ist dabei von der korrekten Anwendung des chemo-mechanischen Aufbereitungsprotokolls abhängig (Keleş et al. 2016; Siqueira 2005, 2013). Dies beinhaltet den mechanischen Abtrag des infizierten Wurzelkanaldentins auf der gesamten Länge, begleitet von einer intensiven Spülung mit verschiedenen Flüssigkeiten, die sich durch antimikrobielle Eigenschaften auszeichnen. Komplexe anatomische Strukturen, wie Isthmen zwischen zwei Kanälen und apikale Ramifikationen, limitieren die mechanische Instrumentierung des komplexen Wurzelkanalsystems, so dass mehr als $50 \%$ der Kanaloberfläche unpräpariert bleiben (Paqué et al. 2005, 2009b). Darüber hinaus werden die während der Präparation entstehenden Dentinspäne (Debris) durch die Instrumente in den Isthmus transportiert. Diese Ansammlung von Debris und Geweberesten im Isthmus erschwert eine adäquate Beseitigung der Mikroorganismen (Mader et al. 1984; Paqué et al. 2011). Dabei ist die Spülung (chemische Komponente) wichtig, um den Debris aus den der Präparation nicht zugänglichen Kanalanteilen zu entfernen (McComb und Smith 1975; Urban et al. 2017). Eine konventionelle Handspülung ist meist nicht in der Lage, den Debris ausreichend zu entfernen (Gu et al. 2009b; Paqué et al. 2011; Ram 1977; Tennert 2013; Verstraeten et al. 2017). Eine Aktivierung der Spülflüssigkeit im Wurzelkanal durch Schall- oder Ultraschall erhöht dagegen die Effektivität der Reinigung (Gu et al. 2009b; Keleş et al. 2016; Urban et al. 2017). 
Die Mikro-Computertomografie (Mikro-CT) findet derzeit eine immer häufigere Verwendung in der Endodontologie. Mithilfe von Mikro-CT-Aufnahmen können unterschiedliche Wurzelkanalpräparationen bewertet (Lacerda et al. 2017), morphologische Besonderheiten dreidimensional dargestellt (Neboda et al. 2018; Verma und Love 2011) oder die Homogenität von Wurzelkanalfüllungen evaluiert werden (Jung et al. 2005).

Derzeit liegen nur wenige Studien vor, die die Entfernung von Debris aus dem Isthmus mithilfe unterschiedlicher Techniken zur Aktivierung der Spülflüssigkeit untersuchen (Freire et al. 2015; Keleş et al. 2016; Leoni et al. 2016; Lloyd et al. 2014; Silva et al. 2019; Versiani et al. 2016).

Das Ziel der vorliegenden Studie war es daher, die Effektivität der schall- und ultraschallaktivierten Wurzelkanalspültechniken zur Entfernung von Debris aus dem Isthmus unterer Molaren zu untersuchen. 


\section{Literaturübersicht}

\subsection{Ziele der Wurzelkanalbehandlung}

Eine Entzündung der Pulpa entsteht durch bakterielle Endotoxine, die über die Dentintubli zur Pulpa gelangen und dort einen Entzündungsmechanismus auslösen. Im Falle eines beständigen bakteriellen Reizes tritt im weiteren Verlauf eine Entzündung des periapikalen Gewebes (Parodontitis apicalis) auf. Um diese periapikale Entzündung zu vermeiden oder eine Ausheilung zu fördern, ist eine adäquate Entfernung der Mikroorganismen aus dem infizierten Wurzelkanalsystem nötig (Rödig et al. 2009).

Das Ziel jeder endodontischen Behandlung muss es deshalb sein, eine adäquate Präparation des Wurzelkanalsystems mit einer anschließenden bakteriendichten Wurzelkanalfüllung zu erreichen. Dadurch wird die Voraussetzung für die Ausheilung des periapikalen Gewebe geschaffen (Gründling et al. 2011; Paqué et al. 2012).

Im Fall einer Pulpanekrose wird das infizierte Dentin durch die mechanische Erweiterung des Wurzelkanals abgetragen und mittels antimikrobiell wirksamen Spülflüssigkeiten die Desinfektion und Reinigung des Kanallumens durchgeführt (van der Sluis et al. 2006).

\subsection{Wurzelkanalpräparation}

Die Präparation der Wurzelkanäle erfolgt mit Handinstrumenten aus Edelstahl oder mittels maschineller Instrumentierung. Bei den Handinstrumenten werden hauptsächlich zwei Grundtypen verwendet. Reamer sind maschinell verdrillte Rohlinge, die in einer drehend-schabenden Arbeitsweise zur Erschließung des Kanals verwendet werden. Ein effizienter Materialabtrag erfolgt anschließend mit den Hedström-Feilen, die eine umlaufende Schneidekannte besitzen und mit einem leichten Anpressdruck ziehend aus dem Kanal verwendet werden (Carrotte 2004). Alle Handinstrumente sind nach der Internationalen Organisation für Normung (ISO) genormt (ISO 2008). Ein Instrument der ISOGröße 15 besitzt an der Instrumentenspitze einen Durchmesser von 0,15 mm. Die Konizität eines Instrumentes wird als .02 angegeben und beschreibt in diesem Beispiel eine Konizität von $2 \%$ und somit einen Durchmesserzuwachs von 0,02 $\mathrm{mm}$ pro Millimeter (ISO 2008). Ein unerwünschter Nachteil der Handinstrumente sind die aufgrund der geringen Flexibilität auftretenden 
Präparationsfehler wie z. B. Kanalbegradigungen oder Stufenbildungen (Hülsmann et al. 2005; Rödig et al. 2009; Schäfer et al. 2000, Tepel et al. 1995).

Aus diesem Grund wird bei gekrümmten Wurzelkanälen die maschinelle Präparation mit Nickel-Titan-Instrumenten (NiTi) bevorzugt, da diese flexibler sind und sich auch nach extremer Biegung in ihre Ausgangsform zurückstellen. Mit speziellen Antriebssystemen können individuell Drehmoment und Umdrehungszahlen für jede einzelne Feile festgelegt und so das Risiko für eine Instrumentenfraktur oder Deformation minimiert werden. Die Instrumente werden rotierend in den Kanal eingebracht und mit kleinen Hubbewegungen maximal 10 bis 15 Sekunden im Kanal verwendet (Rödig et al. 2009; Schäfer und Lohmann 2002).

Die verschiedenen NiTi-Systeme unterscheiden sich in Größe, Konizität, Schneidengeometrie und Anwendung. Dabei gibt es Systeme, die nur ein Instrument für die gesamte Präparation benötigen, andere bestehen aus mehreren Instrumenten mit unterschiedlichen Größen und Konizitäten (Heidemann et al. 2005). Zusätzlich wird zwischen den Arbeitsweisen der Instrumente unterschieden: rotierende NiTi-Systeme drehen sich kontinuierlich um $360^{\circ}$, wohingegen reziprok arbeitende NiTi-Systemen sowohl Drehungen mit und gegen den Uhrzeigersinn durchführen (Heidemann et al. 2005; Rödig et al. 2009; Schäfer und Lohmann 2002).

Ein System mit reziproker Arbeitsweise ist beispielsweise das Reciproc-System. Die Reciproc-Instrumente bestehen aus einer M-Wire Nickel-Titan-Legierung mit großer Flexibilität und einer effizienten Schneidleistung (De-Deus et al. 2013). Der Querschnitt des Instruments ist S-förmig und verfügt über schneidende Außenkanten (Arslan et al. 2016). Es wird in der Crown-downTechnik verwendet, indem Pickbewegungen von koronal nach apikal durchgeführt werden (Jeon et al. 2014).

\subsubsection{Smear layer}

Bei der Präparation und Erweiterung des Wurzelkanallumens entsteht eine Schmierschicht. Dieser smear layer besteht aus organischem und anorganischem Material (Brännström und Johnson 1974). Er setzt sich aus nekrotischem Gewebe, Dentinspänen, Pulpagewebe, Odontoblastenfortsätzen und Bakterien zusammen (McComb und Smith 1975). Mader et al. (1984) unterteilten den smear layer zusätzlich in zwei Typen: Mit einer Schichtstärke von 1-2 $\mu \mathrm{m}$ liegt der oberflächliche smear layer der Wurzelkanalwand auf. Der tiefere smear layer ragt bis zu $40 \mu \mathrm{m}$ in die Dentintubuli hinein. Unter dem 
Rasterelektronenmikroskop zeigt sich eine amorphe, irreguläre und granulare Oberfläche des smear layers (Mader et al. 1984).

Laut derzeitigen Studien wird eine Entfernung der Schmierschicht empfohlen (Violich und Chandler 2010), da ohne eine adäquate Entfernung bakterielle Mikroorganismen zwischen der Wurzelkanalfüllung und der Kanalwand überleben und so eine Reinfektion auslösen können (Brännström und Johnson 1974). Die Schmierschicht unterbindet die Penetration der Spüllösung oder der medikamentösen Einlagen in die Dentintubuli und verhindert somit eine ausreichende Reduktion der Mikroorganismen (McComb und Smith 1975; Shahravan et al. 2007; Violich und Chandler 2010). Die lose Struktur der Schmierschicht ist zusätzlich ein Risiko, da eine bakterielle Besiedlung zwischen Wurzelkanalfüllung und Dentin ein sogenanntes microleakage hervorrufen kann (Mader et al. 1984; Taylor et al. 1997; Violich und Chandler 2010). Daraus folgt, dass durch die Entfernung der Schmierschicht der Sealer besser in die Dentintubuli penetrieren kann und somit die Gefahr einer erneuten Reinfektion durch Bakterien minimiert wird (Hülsmann et al. 2003; White et al. 1984).

Die Entfernung der präparationsbedingten Schmierschicht ist somit ein essentieller Bestandteil eines modernen Spülprotokolls (Jimna et al. 2017; Paragliola et al. 2010; Scelza et al. 2004).

\subsubsection{Debris}

Die lose Auflagerung von Dentinspänen zusammen mit Resten von vitalem oder nekrotischem Gewebe an der Wurzelkanalwand wird als Debris beschrieben (Baumann und Beer 2008). Dabei sammelt sich der durch die Präparation entstandene Debris in Irregularitäten des Kanalsystems wie Isthmen, Nebenkanälen oder apikalen Ramifikationen an (Verstraeten et al. 2017). Die Ansammlung von Debris kann nach Präparation bis zu $6 \%$ des Kanalvolumens mesialer Wurzeln unterer Molaren ausmachen (Arias-Moliz et al. 2016; Paqué et al. 2009a). Dies limitiert die adäquate Reinigung der komplexen anatomischen Strukturen mit antibakteriellen Spülflüssigkeiten (Paqué et al. 2011; Verstraeten et al. 2017). Zusätzlich bietet im Kanal verbliebener Debris ein Substratangebot für Mikroorganismen, die eine Reinfektion des Wurzelkanalsystems hervorrufen und zu einem Misserfolg der endodontischen Therapie führen können (Plotino et al. 2016). Debris hat somit einen ungünstigen Einfluss auf einen bakteriendichten Verschluss einer Wurzelkanalfüllung und muss deswegen mithilfe geeigneter Spüllösungen und -techniken entfernt werden (De-Deus et al. 2008; Paqué et al. 2009a). 


\subsection{Spüllösungen}

Die Wurzelkanalspülung dient im Allgemeinen der Reduktion von Mikroorganismen, der Auflösung und Entfernung von Debris und Schmierschicht sowie zur Unterstützung der mechanischen Instrumentierung. Dabei sollte die Spüllösung eine Reihe von Anforderungen erfüllen. Neben guten antimikrobiellen Eigenschaften muss sowohl vitales als auch nekrotisches Pulpagewebe zersetzt werden. Des Weiteren sollte die Schmierschicht aufgelöst werden und die Spüllösung über eine gute biologische Verträglichkeit verfügen (Barthel et al. 2006). Wichtig ist außerdem, dass die Spülflüssigkeit in die Kanalanteile gelangt, in denen nicht mechanisch präpariert werden kann (McComb und Smith 1975; Urban et al. 2017). Die Spüllösungen sollten mit einer dünnen Kanüle auf Arbeitslänge minus $1 \mathrm{~mm}$ appliziert werden, um ihre Effizienz zu erhöhen (Zehnder 2006). Es gilt zu berücksichtigen, dass bei der Verwendung von nur einer Spüllösung nicht alle Anforderungen erfüllt werden, weshalb eine Kombination aus mehreren Spülflüssigkeiten empfohlen wird (Zehnder 2006).

\subsubsection{Natriumhypochlorit}

Derzeit ist Natriumhypochlorit $(\mathrm{NaOCl})$ die am häufigsten verwendete Spüllösung bei Wurzelkanalbehandlungen (Zehnder 2006). NaOCl weist eine breite antimikrobielle Wirksamkeit gegen Bakterien, Viren und Pilze auf (Ruatala und Weber 1997; Siqueira et al. 2000). In einem mit Bakterien infizierten Wurzelkanalsystem reduziert $\mathrm{NaOCl}$ ihre Anzahl um den Faktor $10^{3}$ $10^{5}$ (Siqueira et al. 2000) und ist somit eine gut antimikrobiell wirksame Substanz (Gründling et al. 2011). Zusätzlich löst $\mathrm{NaOCl}$ den organischen Teil der Schmierschicht auf und kann losen Debris aus dem Wurzelkanalsystem herausspülen (Baumgartner und Mader 1987). Das freie Chlor, welches für die gewebeauflösende und antimikrobielle Wirkung verantwortlich ist, wird jedoch innerhalb weniger Minuten verbraucht. Somit ist eine permanente Zufuhr von frischem $\mathrm{NaOCl}$ notwendig (Zehnder 2006). Da der anorganische Teil der Schmierschicht durch $\mathrm{NaOCl}$ nicht entfernt wird, empfehlen viele Studien eine Kombination aus $\mathrm{NaOCl}$ und Ethylendiamintetraessigsäure (EDTA) (Baumgartner und Mader 1987; Özdemir et al. 2010; Rödig et al. 2010; Siqueira et al. 2010; Zehnder 2006). Nachdem die Präparation der Wurzelkanäle unter permanenter Zufuhr von $\mathrm{NaOCl}$ durchgeführt wurde, bewährt sich eine abschließende Spülung mit EDTA (Jimna et al. 2017; Siqueira et al. 2010; Zehnder 2006). 
In der Endodontologie wird Natriumhypochlorit in Konzentrationen von 0,5\% bis $5,25 \%$ mit einem pH-Wert von 10,7-12,2 verwendet. Dabei haben höhere Konzentrationen keine signifikant bessere antimikrobielle Wirkung (Zehnder 2006). Hohe Konzentrationen weisen allerdings eine erhöhte Toxizität auf die periradikulären Gewebe auf und verringern den Elastizitätsmodul und die Biegefestigkeit des Dentins (Zehnder 2006). Die Verwendung von $\mathrm{NaOCl}$ während der Präparation gilt derzeit aufgrund der hohen antibakteriellen und gewebeauflösenden Wirkung als Standardspülflüssigkeit in der Endodontologie (Hülsmann et al. 2003).

\subsubsection{Ethylendiamintetraessigsäure (EDTA)}

EDTA wurde erstmals als Spüllösung in der Endodontologie von Nygaard-Østby (1957) beschrieben. EDTA ist ein Chelator und besitzt die Fähigkeit, MetallIonen zu binden und somit zu inaktivieren (Hülsmann et al. 2003; Zeeck et al. 1992). Dabei reagiert der Chelator mit Kalzium-Ionen aus dem Hydroxylapatit des Dentins (Çalt und Serper 2002). Die Effizienz ist dabei von der Penetrationstiefe der Spüllösung, der Verweildauer im Wurzelkanalsystem, dem Härtegrad des Dentins und der Konzentration der Spüllösung abhängig (Çalt und Serper 2002; Cury et al. 1981).

Die optimale Verweildauer des EDTA im Wurzelkanalsystem wird kontrovers beurteilt. Yamada et al. (1983) erzielten bereits nach wenigen Sekunden eine deutliche Reduzierung der Schmierschicht. Im Gegensatz dazu empfahlen Goldberg und Spielberg (1982) eine Anwendung von bis zu $15 \mathrm{~min}$. Die Wirkung des EDTA beruht auf dem Auflösen des anorganischen Anteils des smear layers, wobei gleichzeitig die Dentintubuli erweitert, die Kollagenfasern denaturiert und das Dentin demineralisiert werden (De-Deus et al. 2006, 2011; Garberoglio und Becce 1994; McComb und Smith 1975). Çalt et al. (2002) beschrieben, dass die Verwendung einer 17 \%igen EDTA-Lösung für eine Minute nur leichte Erosionen hervorruft und die Schmierschicht zum größten Teil entfernt. Bei einer Anwendung von 10 min wiesen die Zähne exzessive Erosionen im peri- und intertubulären Bereich des Dentins auf (Çalt und Serper 2002). Der tubuläre Durchmesser verdoppelte sich im Vergleich zur Anwendung von einer Minute und erreichte einen Durchmesser bis zu $4 \mu \mathrm{m}$ (Çalt und Serper 2002). Mehrheitlich wird daher eine Verwendung zwischen einer bis fünf Minuten empfohlen (Çalt und Serper 2000; Hülsmann et al. 2003; Yamada et al. 1983). 
EDTA wird für die Auflösung der anorganischen Bestandteile der Schmierschicht empfohlen und daher nach der Präparation angewendet (Zehnder 2006).

\subsection{Techniken der Wurzelkanalspülung}

\subsubsection{Handspülung}

Die manuelle Handspülung ist die am weitesten verbreitete Spülmethode in der Endodontologie. Dabei wird die Spüllösung unter Verwendung einer Einmalspritze mit einer stumpfen Kanüle in den Wurzelkanal appliziert. Die Kanüle darf dabei keine Klemmpassung aufweisen, damit der Debris nach koronal aus dem Kanal herausgespült und Schädigungen des periapikalen Gewebes vermieden werden ( $\mathrm{Gu}$ et al. 2009b). Stumpfe Kanülen sind in verschiedenen Größen und Ausführungen verfügbar, wobei die Öffnung seitlich oder am Ende gelegen sein kann (Kahn et al. 1995). Die Spüllösung dringt nach Austritt aus der Kanüle nur ungefähr 1-2 Millimeter in den Wurzelkanal ein (Ram 1977). Der Vorteil der manuellen Handspülung liegt darin, dass eine gute Kontrolle über die Eindringtiefe und das Applikationsvolumen vorliegt (van der Sluis et al. 2006). Bei einer komplexen Wurzelkanalanatomie zeigt die Handspülung jedoch Limitationen, weil es nicht gelingt, Debris aus Isthmen und Ramifikationen zu entfernen sowie eine effektive Auflösung der Schmierschicht zu erzielen (Nair et al. 2005; Wu und Wesselink 2001). Zudem ist die Handspülung problematisch, wenn der Wurzelkanal eine Präparationsgröße von weniger als ISO 35-40 aufweist (Falk und Sedgley 2005). Eine Applikation der Spüllösung auf Arbeitslänge $(A L)$ minus $1 \mathrm{~mm}$ erzielte eine dreimal so hohe Reinigungswirkung wie die Applikation auf AL minus $5 \mathrm{~mm}$ (Perez et al. 2016). In einer vergleichbaren Mikro-CT-Studie wurde der Debrisanteil im Isthmus unterer Molaren durch die Handspülung mit EDTA von 6,9 Vol.-\% auf 4,9 Vol.-\% reduziert (Paqué et al. 2011). Allerdings schnitt die Handspülung in einer weiteren Mikro-CT-Untersuchung hinsichtlich der Entfernung von Debris aus dem Isthmus signifikant schlechter als ein Unterdrucksystem (EndoVac) ab (Versiani et al. 2016).

\subsubsection{Schallaktivierung}

Eine Aktivierung der Spülflüssigkeit trägt deutlich zur Verbesserung der Wurzelkanaldesinfektion und Reinigung bei (Gu et al. 2009b; Rödig et al. 2010; Urban et al. 2017; Zehnder 2006). Die Schallaktivierung fand erstmals 1985 in der Endodontologie Verwendung (Tronstad et al. 1985) und gilt als effektive 
Methode zur Desinfektion des Wurzelkanalsystems (Pitt 2005). Im Vergleich zur Ultraschallaktivierung wird bei der Schallaktivierung mit niedrigeren Frequenzen von $166 \mathrm{~Hz}$ (EndoActivator) bis zu $6000 \mathrm{~Hz}$ (EDDY) gearbeitet (Ahmad et al. 1987a; Gu et al. 2009b; Urban et al. 2017).

\subsubsection{EDDY (ED)}

EDDY (Abbildung 1) ist eine flexible Polyamid-Spitze in der Größe 25 (VDW 2017). Der EDDY wird mit einem Sonic-Handstück und einer Frequenz von 5000-6000 Hz betrieben. Laut Hersteller kreiert der EDDY eine dreidimensionale Bewegung und erzeugt dabei hydrodynamische Strömungen innerhalb der Spülflüssigkeit (VDW 2017). Hydrodynamische Strömungen beschreiben schnelle und kreisförmige Flüssigkeitsbewegungen um die Polyamid-Spitze herum (Mozo et al. 2012). Somit gelingt es, die Spülflüssigkeit auch in komplexe Bereiche des Wurzelkanalsystems zu transportieren. Das flexible Polyamid trägt kein Dentin ab und ist somit auch in gekrümmten Wurzelkanälen ohne die Gefahr der Stufenbildung verwendbar (VDW 2017). In einer Studie zur Reinigungswirkung des EDDY wurde eine signifikante Verbesserung hinsichtlich der Entfernung von Schmierschicht und Debris im Vergleich zur Handspülung mittels Elektronenmikroskop festgestellt (Urban et al. 2017).

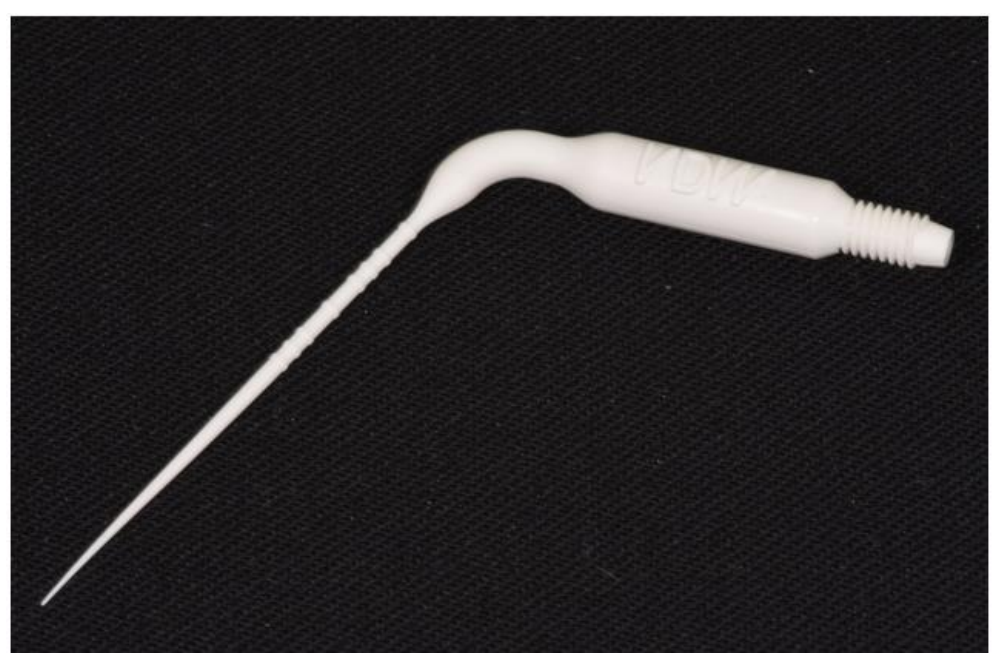

Abbildung 1: Schallaktivierbarer Polyamid-Aufsatz EDDY

In einer weiteren Studie wurden Oberkiefer-Frontzähne in Längsrichtung gespalten und anschließend in jeweils einer Wurzelhälfte eine standardisierte Grube präpariert (Conde et al. 2017). In diese Grube wurden Schleimhautproben von Schweinen eingebracht, die Wurzelhälften repositioniert und gewogen. Die ermittelte Gewichtsreduktion der Proben nach Spülungsaktivierung ergab eine signifikante Verbesserung der Reinigungswirkung und 
Gewebeauflösung bei EDDY-Anwendung im Vergleich zur konventionellen Handspülung (Conde et al. 2017).

Eine kürzlich veröffentlichte Mikro-CT-Studie verwendete anstelle extrahierter Zähnen transparente Plastikblöcke, in denen ein standardisiertes Wurzelkanalsystem einschließlich Isthmus eingelassen war. Das dort eingebrachte Hydrogel-Debris-Gemisch wurde durch die Anwendung des EDDY signifikant besser als durch die Handspülung entfernt (Swimberghe et al. 2019).

\subsubsection{EndoActivator (EA)}

Der EndoActivator (Abbildung 2) ist ein kabelloses Handstück, das mit flexiblen Polymer-Aufsätzen in den Größen 15/.02, 25/.04 und 35/.04 bestückt wird. Dabei lässt sich das Handstück auf eine Frequenz von 160, 175 oder $190 \mathrm{~Hz}$ einstellen (Bryce et al. 2018; Jiang et al. 2010). Der EA produziert durch das Oszillieren der weichen und hochflexiblen Polymer-Spitze hydrodynamische Strömungen innerhalb der Spüllösung (Virdee et al. 2018). Weiterhin fördert der EA die Penetration der Spülflüssigkeit in apikale Bereiche und Isthmen (Paragliola et al. 2010) und erzielt somit eine verbesserte Entfernung von Debris und Schmierschicht im Vergleich zur manuellen Handspülung (Caron et al. 2010).
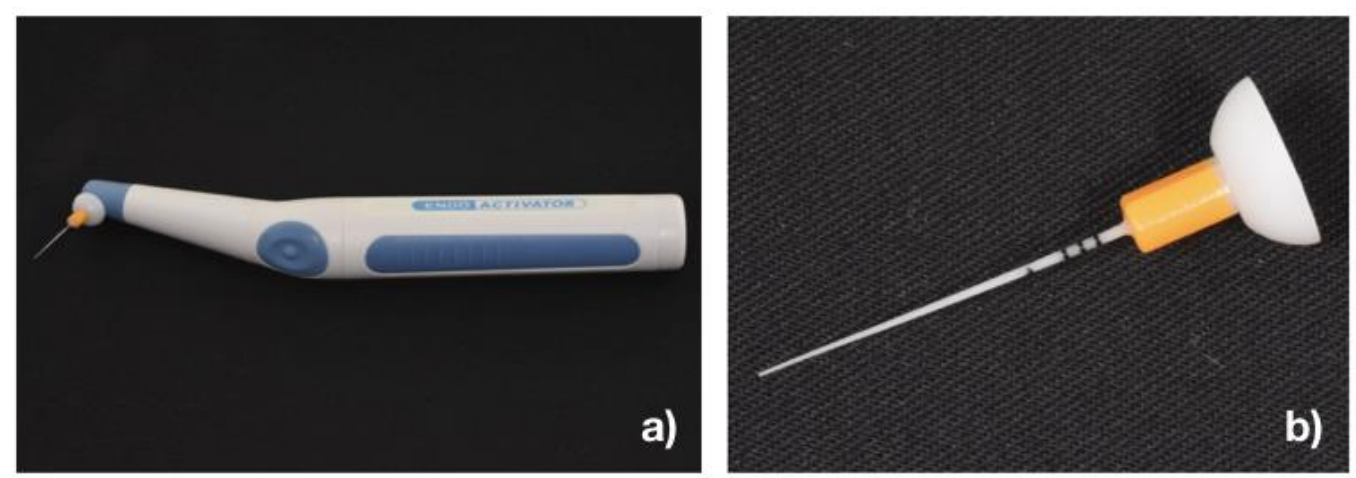

Abbildung 2: a) EndoActivator, b) EndoActivator-Aufsatz der Größe 15/.02

Laut Studien erzielte der EA im Vergleich zur Ultraschallaktivierung eine bessere Reinigung im koronalen und mittleren Anteil des Wurzelkanalsystems (Schiavotelo et al. 2017). Im apikalen Bereich zeigten sich allerdings keine Unterschiede (Caron et al. 2010; Rödig et al. 2010; Schiavotelo et al. 2017). Hinsichtlich der Debrisentfernung aus künstlichen Isthmen wies der EA keine signifikant bessere Reinigungswirkung als die Handspülung auf (Swimberghe et al. 2019). 


\subsubsection{Ultraschallaktivierung (US)}

Die Ultraschallaktivierung der Spülflüssigkeit ist seit dem Jahre 1957 in der Endodontologie in Gebrauch (Richman 1957). Dabei werden die Feilen bei einer Frequenz von 25-30 kHz in Schwingungen versetzt (Gu et al. 2009b).

Man unterscheidet zwischen zwei verschiedenen Anwendungen: Zum einen gibt es die aktive Ultraschallaktivierung mit gleichzeitiger Instrumentierung, zum anderen die passive Ultraschallaktivierung der Spülflüssigkeit. Die aktive Ultraschallaktivierung hat den Nachteil, dass das Instrument Kontakt mit den Dentinwänden aufweist und somit zum unkontrollierten Abtrag von Dentin führt (Archer et al. 1992; Gu et al. 2009b). Dabei können Stufenbildungen in der Kanalwand, Perforationen oder unbeabsichtigte Überinstrumentierungen eine Folge sein (Klyn et al. 2010; van der Sluis et al. 2007). Bei der passiven Ultraschallaktivierung (US) der Spülflüssigkeit findet ein dünnes, nicht schneidendes Instrument Verwendung (Abbildung 3), das über ein Ultraschallgerät betrieben wird (Sabins et al. 2003).

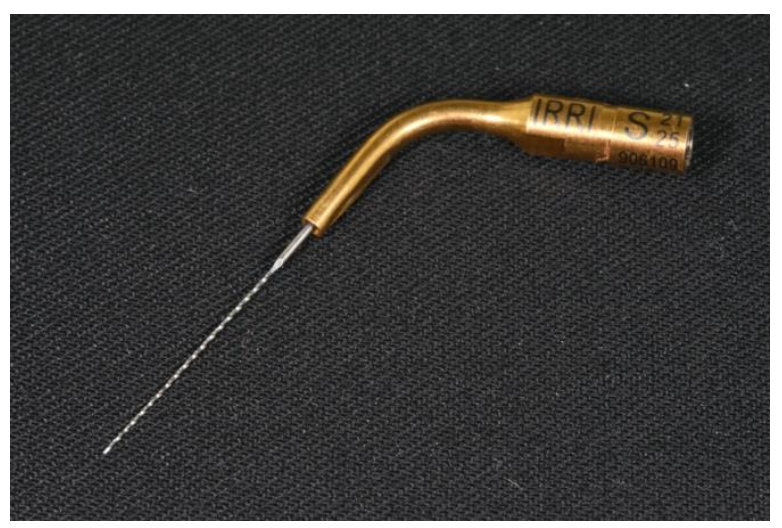

Abbildung 3: Ultraschallaufsatz IRRI S der Größe 25

Die elektrische Energie des Gerätes wird über piezoelektrische oder magnetostriktive Effekte als Ultraschallwelle weitergeleitet. Diese Ultraschallwellen versetzen das Instrument in Schwingungen, welche wiederum in der Spülflüssigkeit hydrodynamische Muster erzeugen, die als Schwingungsbäuche und -knoten beschrieben werden (van der Sluis et al. 2007). Generell spricht man davon, dass die hochfrequenten Schwingungen des Instrumentes akustische Strömungen und Kavitationen auslösen (Ahmad et al. 1987b). Kavitation beschreibt das Implodieren von Luftblasen in einer Flüssigkeit durch eine einwirkende Kraft, wodurch Energie freigesetzt und somit eine verbesserte Reinigungswirkung der Spülflüssigkeit erzielt wird (Roy et al. 1994).

Eine akustische Strömung ist eine schnelle kreisförmige Bewegung einer Flüssigkeit und wird im Wurzelkanal als Mikroströmung bezeichnet (van der 
Sluis et al. 2007). Diese Mikroströmungen bewegen die Spülflüssigkeit in Richtung der Dentinwände und fördern die mechanische Reinigung und die Zerstörung der Bakterien (Al-Jadaa et al. 2009). Zusätzlich gelangt die Spülflüssigkeit in Seitenkanäle und Isthmen (de Gregorio et al. 2009; Mozo et al. 2012). Wenn das ultraschallaktivierte Instrument nicht frei im Wurzelkanal schwingen kann, wird die Oszillation gedämpft und somit die Wirkung der Mikroströmungen reduziert (Roy et al. 1994).

Generell liegt die Frequenz bei der Ultraschallaktivierung zwischen $25-30 \mathrm{kHz}$, wobei die Amplitude des Instruments ungefähr 20-100 $\mu$ m beträgt (Ahmad et al. 1988). Die Amplitude ist an der Spitze am größten, weshalb ein direkter Einfluss von Frequenz und Abstand zur Arbeitslänge des Wurzelkanals besteht (Jiang et al. 2011). Es wird dabei empfohlen die Ultraschallspitze auf einer Arbeitslänge minus 1-2 mm zu aktivieren, um den Debris optimal zu entfernen (Vivan et al. 2016).

Eine Vielzahl von Studien wies eine deutliche Überlegenheit der Ultraschallaktivierung im Vergleich zur konventionellen Handspülung in Bezug auf die Debris- und Schmierschicht-Entfernung nach (Conde et al. 2017; Leoni et al. 2016; Paqué et al. 2011; van der Sluis et al. 2007). Im apikalen Bereich erreichte die Ultraschallaktivierung eine Verbesserung der Debrisentfernung im Vergleich zur Schallaktivierung (Mozo et al. 2012; Rödig et al. 2010; Urban et al. 2017). In einer weiteren Studie wurde eine vermehrte Debris- und Schmierschicht-Entfernung im apikalen Drittel des Wurzelkanals bei der Ultraschall- im Vergleich zu Schallaktivierung beobachtet (Sabins et al. 2003). Schiavotelo et al. (2017) stellten allerdings fest, dass der EndoActivator der Ultraschallaktivierung im mittleren und koronalen Anteil des Wurzelkanalsystems hinsichtlich der Debris- und Schmierschicht-Entfernung überlegen ist.

Während der Ultraschallaktivierung der Spülflüssigkeit besteht immer eine Gefahr der Instrumentenfraktur oder der Dentinschädigung (Boutsioukis et al. 2013). Allerdings wird die Ultraschallaktivierung hinsichtlich einer apikalen Extrusion von Spüllösung als sicher eingestuft, da das Instrument größtenteils laterale Strömungsphänomene generiert (Jiang et al. 2011).

Für die Dauer der Ultraschallaktivierung gibt es keine genauen Empfehlungen. Sabins et al. (2003) stellten fest, dass kein signifikanter Unterschied zwischen $30 \mathrm{~s}$ und $60 \mathrm{~s}$ Aktivierung in Bezug auf die Debrisentfernung messbar ist. Weiterhin wurde kein signifikanter Unterschied hinsichtlich der Entfernung von Debris aus einer standardisierten Grube in einem Wurzelkanal bei 1- bzw. 3minütiger Ultraschallaktivierung festgestellt (van der Sluis und Wu 2009). 
Im mesialen Kanalsystem von Unterkiefer-Molaren mit einem Isthmus wurde mit Ultraschall eine signifikante Debrisreduzierung im Vergleich zu fehlender Spülungsaktivierung erzielt (Verstraeten et al. 2017). In einer weiteren Studie erzielte die Ultraschallaktivierung ebenfalls eine signifikante Reduktion des Debris im Isthmus und gleichwertige Ergebnisse im Vergleich zur Spülungsaktivierung mit EndoVac und der Self-Adjusting-File (Silva et al. 2019).

\subsection{Evaluierung und Darstellung des Debris}

\subsubsection{Die Mikro-Computertomografie}

Bisher wurde Debris im Wurzelkanalsystem entweder histologisch, elektronenmikroskopisch oder mithilfe von Schnittpräparaten nachgewiesen (Gutarts et al. 2005; Rödig et al. 2010; Schiavotelo et al. 2017; Urban et al. 2017). Allerdings kann die Herstellung von Schnittpräparaten dazu führen, dass sich Volumen und Lokalisation des Debris ändern (Robinson et al. 2012). Zusätzlich ist die Darstellung des Pulpagewebes bei einer zweidimensionalen Abbildung eingeschränkt (Nielsen et al. 1995) und lässt somit nur die Beurteilung von Abschnitten des jeweiligen Zahnes zu (Freire et al. 2015). Des Weiteren unterliegen die elektronenmikroskopischen Aufnahmen einer quantitativ und qualitativ subjektiven Beurteilung des Untersuchers (De-Deus et al. 2011).

Die Darstellung des Endodonts mithilfe der Mikro-Computertomografie (MikroCT) stellt ein nicht invasives Bildgebungsverfahren dar, bei der Messungen der Zähne zu unterschiedlichen Zeitpunkten erfolgen können (Nielsen et al. 1995). Dabei werden mittels Röntgenstrahlung hochauflösende TomografieProjektionsbilder eines Zahnes erstellt, die anschließend zu einem dreidimensionalen Modell rekonstruiert werden (Robinson et al. 2012).

Der Unterschied zur Computertomografie (CT) liegt im Wesentlichen in der Auflösung. Während bei der CT eine Auflösung von $1 \mathrm{~mm}$ erreicht wird, ist bei der Mikro-CT eine Auflösung zwischen 5 und $50 \mu \mathrm{m}$ möglich. Dies gelingt unter der Verwendung von Synchrotronstrahlungsquellen oder optimierter Fein- und Mikrofokusröntgenröhren. Das Objekt rotiert im Mikro-CT auf einem Objektträger um $180^{\circ}$ (Abbildung 4). 


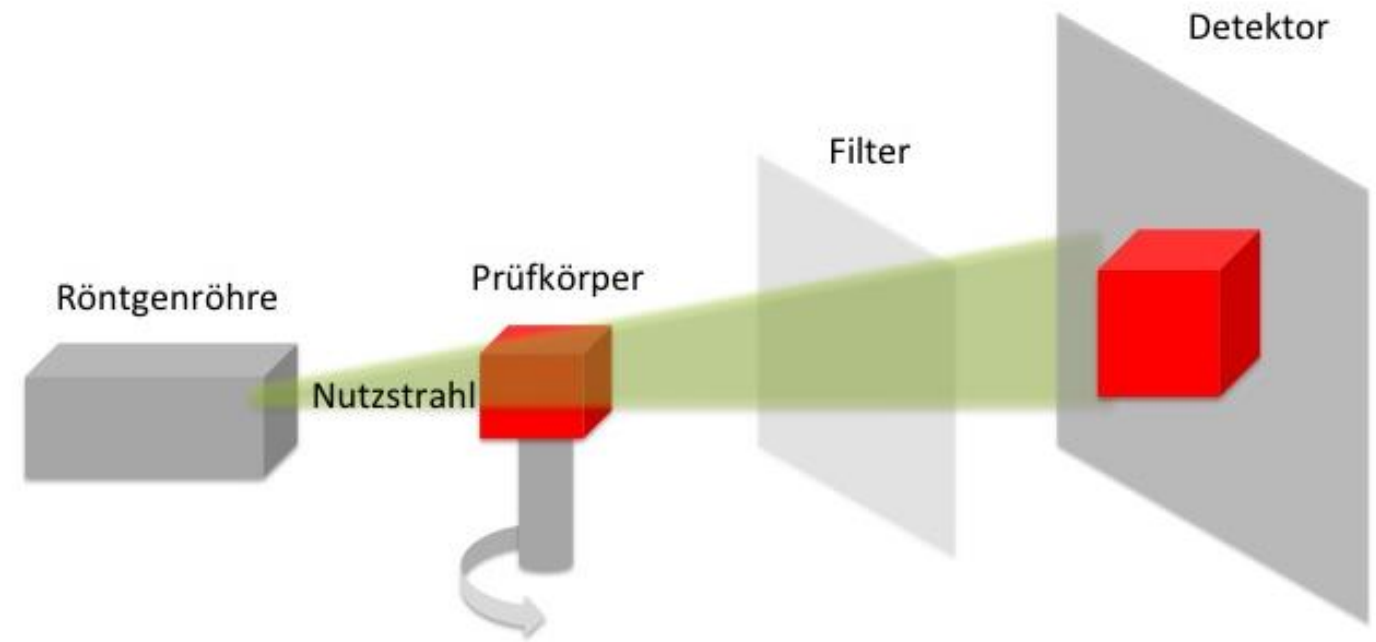

Abbildung 4: Schematische Darstellung eines Mikro-CTs. Der rote Prüfkörper rotiert auf einem Objektträger um $180^{\circ}$ und wird vollständig vom Detektor erfasst.

Die Nachteile des Mikro-CTs liegen in der Limitierung des kleinen Probendurchmessers von maximal $75 \mathrm{~mm}$ sowie in der Generierung und Speicherung von sehr großen Datensätzen von ca. 270-2150 MB (Engelke et al. 1999) bis ca. 4 GB in der vorliegenden Studie. Das Anwendungsspektrum der Mikro-Computertomografie (Mikro-CT) weitet sich im Forschungsbereich der Endodontologie immer weiter aus. Es veranschaulicht bildlich die komplexe Wurzelkanalanatomie mit ihren Ramifikationen und Isthmen. Diese gelten als limitierende Faktoren während der Wurzelkanalpräparation und -spülung und stellen somit die Schwierigkeit einer erfolgreichen endodontischen Behandlung da (Freire et al. 2015).

Verma et al. (2011) untersuchten anhand der dreidimensionalen Darstellung mittels Mikro-CT die Morphologie mesiobukkaler Wurzelkanäle oberer Molaren. Bei mesialen Wurzeln unterer Molaren wurden folgende Bezeichnungen für verschiedene Isthmi-Konfigurationen vorgeschlagen: Flossenförmige, netzartige und bandartige Verbindungen zwischen dem mesiobukkalen und mesiolingualen Wurzelkanal (Gu et al. 2009a).

Eine weitere Studie untersuchte mithilfe des Mikro-CTs die Veränderung des Kanalvolumens und der Dentindicke nach Entfernung intrakanalärer Instrumentenfragmente mittels Ultraschall (Garg und Grewal 2016). Darüber hinaus stellten Jung et al. (2005) einen Vergleich der Genauigkeit zwischen Mikro-CT und Elektronenmikroskop auf. Dabei evaluierten sie die Darstellung der Wurzelkanalfüllung zuerst mittels Mikro-CT und anschließend histologisch 
unter dem Elektronenmikroskop. Es wurde auf die Genauigkeit der Abbildungsschärfe zwischen Zahnhartsubstanz, Sealer und Guttapercha geachtet. Dabei wurde eine hohe Korrelation zwischen histologischer Untersuchung und Mikro-CT-Auswertung in quantitativer und qualitativer Hinsicht erreicht (Jung et al. 2005).

Die Mikro-CT-Technik wird zusätzlich verwendet, um die Wurzelkanalpräparation mit maschinellen NiTi-Systemen zu analysieren. Dabei wurden Scans vor und nach der Präparation angefertigt, um die Veränderung des Kanalvolumens und der -oberfläche sowie die Kanalbegradigung zu berechnen (Paqué et al. 2009b; Peters et al. 2001). Weiterhin wurde der Effekt einer apikalen Erweiterung in Bezug auf den nicht präparierten Kanalwandanteil ermittelt (Perez et al. 2017). Dabei wurde bei einer größeren apikalen Erweiterung eine signifikante Reduktion des nicht präparierten Kanalwandanteils festgestellt (Perez et al. 2018).

Die Ansammlung von Debris im Isthmusbereich (Abbildung 5) wurde erstmals von Paqué et al. (2009a) untersucht. Dabei wurden mesiale Wurzeln unterer Molaren präoperativ eingescannt, anschließend wurden die Wurzelkanäle maschinell ohne Spülung präpariert und erneut gescannt. Insgesamt waren 29,2 Vol.- $\% \pm 14,5$ Vol.- $\%$ des präoperativen Kanalvolumens mit Debris gefüllt. Debris wurde dabei als Material mit identischer Röntgenopazität wie Dentin definiert, das sich nach der Präparation im Isthmus befand (Paqué et al. 2009a). 


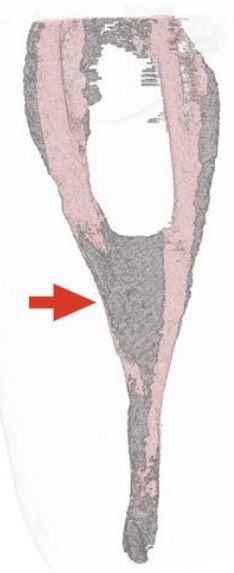

Abbildung 5: Mikro-CT-Darstellung eines mesialen Wurzelkanalsystems. Der rote Pfeil deutet auf die Debrisansammlung (grau) im Isthmus nach maschineller Präparation.

Weitere Studien beschäftigten sich mit einer Optimierung verschiedener Spülprotokolle, um den Debris möglichst effektiv aus dem Isthmus zu entfernen (Freire et al. 2015; Keleş et al. 2016; Leoni et al. 2016; Lloyd et al. 2014; Versiani et al. 2016). Lloyd et al. (2014) stellten die 2,6-fache Verbesserung der Debrisentfernung mit laseraktivierter Spülung im Vergleich zur Handspülung fest. Leoni et al. (2016) erreichten eine Debrisreduktion von 94,1 \% mit einer Ultraschallaktivierung über drei Zyklen á $20 \mathrm{sec}$ im Gegensatz zur Handspülung $(45,7 \%)$. In einer weiteren Untersuchung wurde eine deutliche Reduktion des Debrisvolumens nach Spülungsaktivierung festgestellt und mittels Mikro-CT visualisiert (Freire et al. 2015; Keleş et al. 2016; Versiani et al. 2016). In keiner Untersuchung wurde allerdings eine vollständige Eliminierung des Debris erreicht. Häufig lag das Problem in der unvollständigen Entfernung von Debris im apikalen Kanaldrittel und aus dem Isthmus (Keleş et al. 2016; Paqué et al. 2012).

In der vorliegenden Studie wurde der Mikro-Computertomograf Skyscan 1272 der Firma Bruker verwendet. Der Skyscan 1272 hat den Vorteil, dass sich die Strahlenquelle und der Detektor um das Objekt bewegen, um so möglichst hohe Auflösungen von bis zu 200 Megapixel bei einer minimalen Objektgröße von $0,35 \mu \mathrm{m}$ zu generieren.

Für eine weitere Verarbeitung der zweidimensionalen TomografieProjektionsbilder, werden verschiedene Softwareprogramme benötigt. Die Software NRecon (Version 1.7.3.0) rekonstruiert aus den TomografieProjektionsbildern zweidimensionale Querschnittsbilder. Da während jedes 
Scans unterschiedliche Artefakte oder Verzerrungen im Bild auftreten können, werden verschiedene Parameter zur Minimierung der Störfaktoren eingestellt.

Die Funktion ring artifacts reduction reduziert die entstandenen Ringartefakte im Querschnittsbild. Dabei müssen die Werte so ausgewählt werden, dass keine unnötige Unschärfe entsteht bei gleichzeitiger Entfernung der Ringartefakte (Abbildung 6). Diese Ringartefakte können beispielsweise durch Schäden am Detektor oder fehlender Kalibrierung des Mikro-CTs entstehen (Queiroz et al. 2017a).
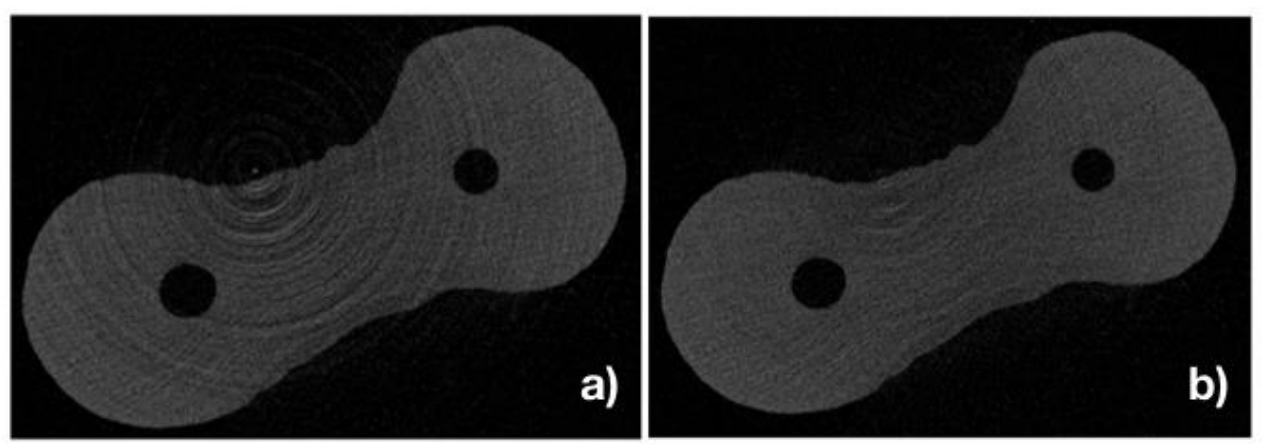

Abbildung 6: Ringartefakte vor (a) und nach (b) der Korrektur

Das smoothing glättet jeden einzelnen Pixel, wodurch Störfaktoren im Bild beseitigt werden.

Die Funktion beam-hardening korrigiert den Strahlhärtungseffekt. Je nach Dichte des Scanobjektes können Korrekturen von 0-100 \% ausgewählt werden. Aufgrund der polyenergetischen Eigenschaft der Röntgenstrahlung können die Artefakte auch unter Anwendungen eines Kupfer- oder Aluminiumfilters nicht vollständig eliminiert werden.

Mit dem post-alignment erfolgt ein Nachabgleich des Scans, um Ausrichtungsfehler, die während der Rotation des Objekts auftreten, auszugleichen (Abbildung 7). Dabei muss der Wert präzise ausgewählt werden, da sonst Verdoppelungen oder Verzerrungen des Bildes entstehen können. Diese Artefakte entstehen durch Erschütterungen des Gerätes während des Scanvorgangs. 

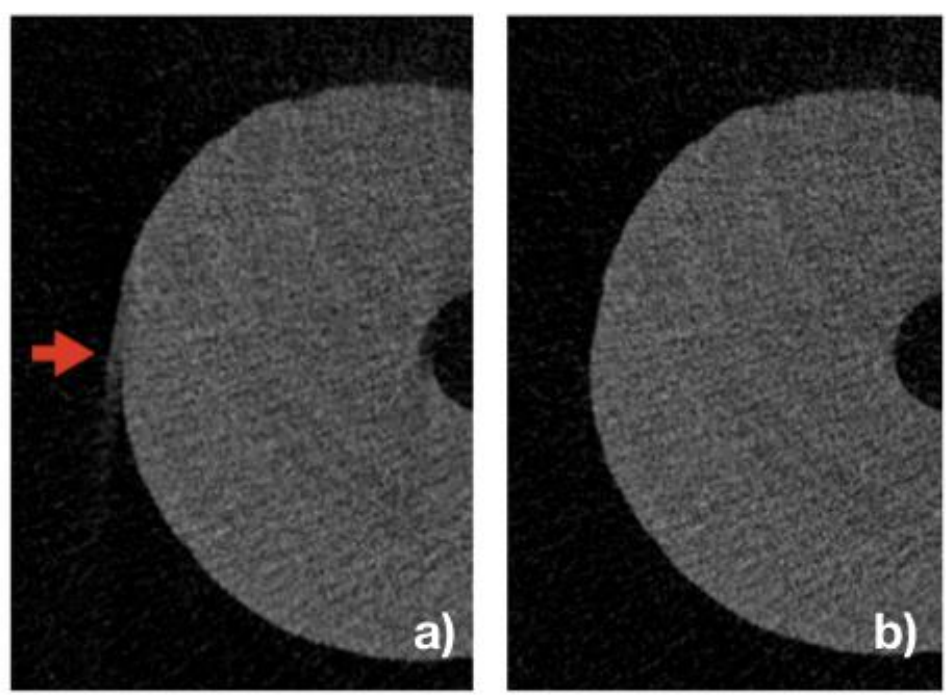

Abbildung 7: Post-alignment-Einstellung: Der rote Pfeil zeigt in (a) auf eine Verzerrung, die durch die richtige Einstellung in (b) korrigiert wurde.

Anschließend werden die Querschnittsbilder für die weitere Verarbeitung in ein Bearbeitungsprogramm importiert. In der vorliegenden Studie wurde das Programm CTAnalyzer (Version 1.17.7.2) benutzt. Zur Auswertung der Querschnittsbilder wird eine Binarisierung durchgeführt, die ein Graustufenbild in ein Schwarzweißbild umwandelt. Dabei bilden die schwarzen Pixel den Hintergrund und die weißen Pixel das gescannte Objekt ab (Jirik et al. 2018). Dies geschieht durch die Ausführung der Funktion thresholding (Abbildung 8) (Queiroz et al. 2017b).
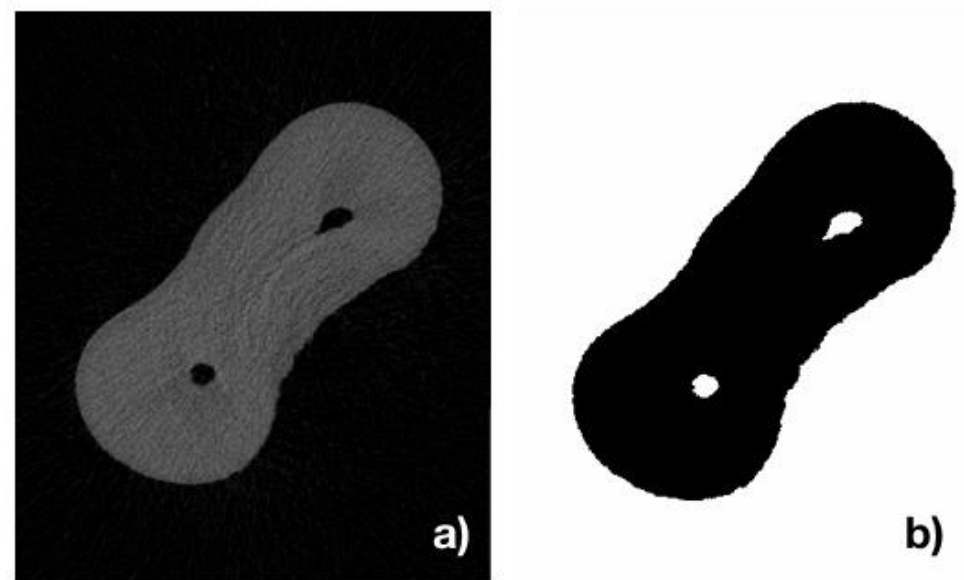

a)

b)

Abbildung 8: Wurzelquerschnitt im CTAnalyzer vor (a) und nach (b) Durchführung des thresholding

Die Auswahl des richtigen Intensitätsbereiches der Graustufen ist dabei sehr entscheidend, da es einen großen Effekt auf die Bildanalyse hat. Ein 
Intensitätsbereich von 0-40 ist gut, um Dentin zu identifizieren und von der Umgebung abzugrenzen (Robinson et al. 2012). Die dreidimensionale Darstellung des Zahnes erfolgt abschließend mit der Software CTVox (Version 3.2) (Abbildung 9).

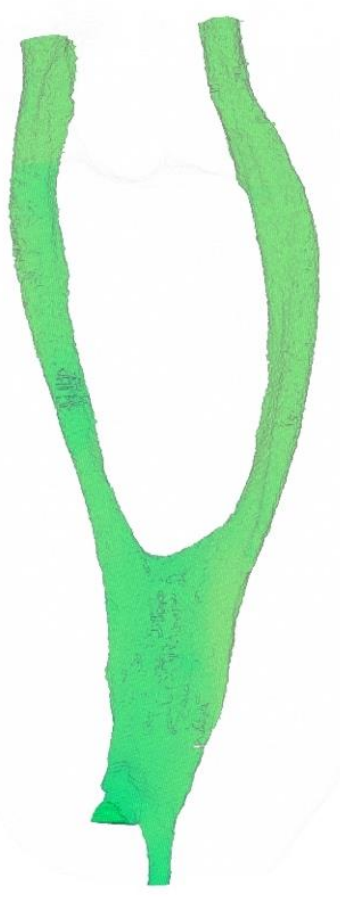

Abbildung 9: Mikro-CT-Abbildung eines rekonstruierten Wurzelkanalsystems mithilfe der Software CTVox. 


\section{Zielsetzung}

Das Ziel der vorliegenden In-vitro-Studie war es, die Effektivität zweier schallund einer ultraschallaktivierten Wurzelkanalspültechniken zur Entfernung von Debris aus dem Isthmus unterer Molaren mithilfe des Mikro-CTs nachzuweisen. Diese Ergebnisse wurden anschließend mit der Reinigungs-wirkung der Handspülung verglichen. 


\section{Material und Methode}

\subsection{Versuchsdurchführung}

\subsubsection{Vorauswahl des Untersuchungsmaterials}

Nach Genehmigung des Ethikantrages (Antragsnummer 27/8/13) wurden für die Versuche 110 extrahierte menschliche Unterkiefermolaren gesammelt und in $0,1 \%$ thymolhaltigem Leitungswasser gelagert. Die Extraktion der Zähne erfolgte aus parodontologischen Gründen und stand nicht im Zusammenhang mit der durchgeführten Studie. Vorhandene Konkremente wurden mithilfe eines Scalers von der Wurzeloberfläche entfernt. Anschließend wurde an allen Zähnen die mesiale Wurzel mit einer Lindemannfräse an der Bifurkation von der distalen Wurzel separiert und mit einem Diamantbohrer trepaniert. Die apikale Gängigkeit beider Kanäle wurde mit Reamern der ISO-Größe 10 überprüft und der Wurzelkanalverlauf röntgenologisch in zwei Ebenen dargestellt. Um eine mögliche Verzerrung des digitalen Röntgenbildes festzustellen, wurde ein $1 \mathrm{~cm}$ langer Metallstab als Referenz mitgeröntgt (Abbildung 10).

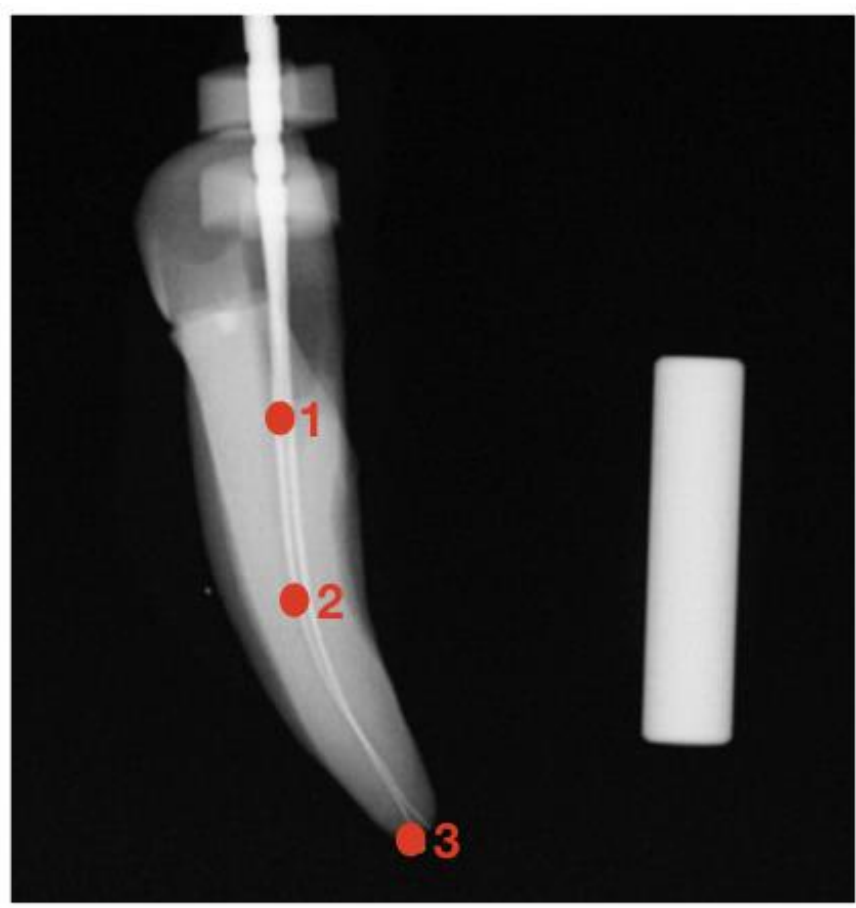

Abbildung 10: Digitales Röntgenbild in bukko-lingualer Richtung inklusive Markierungen für die Bestimmung der Wurzelkanalkrümmung. Die markierten Punkte entsprechen dabei 1. Kanaleingang, 2. Beginn der Krümmung, 3. Apex 
Es wurden ausschließlich Wurzeln mit einer Kanalkonfiguration der VertucciKlasse II verwendet (Abbildung 11), d. h. koronal waren zwei separate Wurzelkanäle vorhanden, die sich apikal vereinigten (Vertucci 1984). Anschließend wurden die Krümmungswinkel und -radien der Wurzeln mithilfe des bukko-lingualen Röntgenbildes ermittelt. Dazu wurden mit ImageJ (Version 2.0.0-rc-43/1.51j) drei Koordinaten im Röntgenbild festgelegt: der Kanaleingang, der Beginn der Krümmung und der röntgenologische Apex (Abbildung 10). Anhand dieser drei Punkte und einer programmierten Formel in Excel wurden der Krümmungswinkel nach Schneider (1971) und der Radius nach Schäfer (2002a) errechnet.

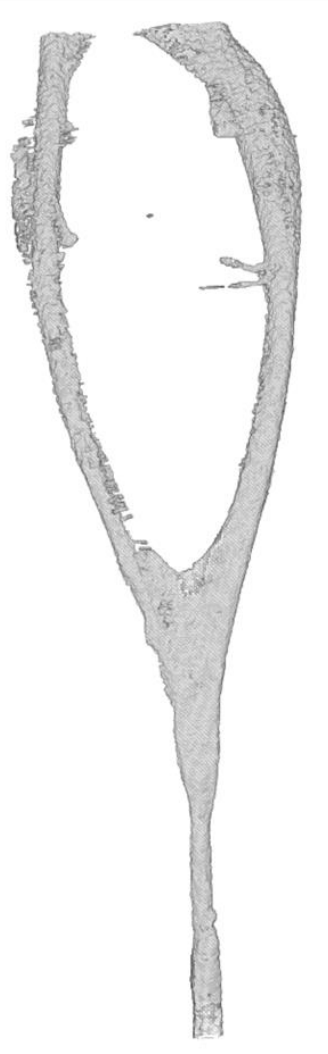

Abbildung 11: Mikro-CT-Aufnahme einer mesialen Wurzel eines unteren Molaren mit dem Verlauf des mesio-bukkalen und mesio-lingualen Wurzelkanals entsprechend der Vertucci-Klasse II (mesio-distale Projektionsrichtung).

Alle Wurzeln, die einen Krümmungswinkel von $10-25^{\circ}$ und einen Radius zwischen 5,5 mm und 16,5 $\mathrm{mm}$ aufwiesen, wurden bei 21,9 $\mu \mathrm{m}$ unter $90 \mathrm{kV}$ und $111 \mu \mathrm{A}$ mit einem $\mathrm{Al} 0,5+\mathrm{Cu}$ 0,038 Filter für $4 \mathrm{~min}$ in einem MikroComputertomografen (Bruker Skyscan 1272 Mikro-CT) eingescannt. Mit Nrecon (Version 1.7.3.0) wurden die Vorscans der Wurzeln zunächst rekonstruiert und nachfolgend der Kanalverlauf mit CTvox (Version 3.2) 3-dimensional (3D) 
dargestellt. Von den 110 Zähnen erfüllten abschließend 40 Wurzeln die folgenden Auswahlkriterien (Tabelle 1).

Tabelle 1: Auswahlkriterien der Versuchszähne

\begin{tabular}{|ll|}
\hline$\bullet$ & Abgeschlossenes Wurzelwachstum \\
\hline$\bullet$ & Keine Wurzelkanalfüllung \\
\hline$\bullet$ & Durchgängigkeit mit einem Reamer ISO-Größe 10 bis apikal \\
\hline$\bullet$ & Vertucci-Klasse II \\
\hline$\bullet$ & Wurzelkanalkrümmungswinkel zwischen $10^{\circ}-25^{\circ}$, -radius zwischen \\
& $5,5 \mathrm{~mm}-16,5 \mathrm{~mm}$ \\
\end{tabular}

\subsubsection{Vorbereitung der Zähne}

Um ein geschlossenes Kanalsystem zu simulieren, wurde das apikale Foramen mit Heißkleber abgedichtet. Die Trennstelle an der Bifurkation wurde nach Konditionierung mit OptiBond $\mathrm{FL}$ mit einer $1 \mathrm{~mm}$ hohen Kompositfüllung verschlossen, um auf diese Weise das Pulpakavum wiederherzustellen und ein Reservoir für die Spülflüssigkeit zu schaffen (Abbildung 12).

Mit einem Diamantbohrer wurden die Wurzeln von koronal auf eine einheitliche Länge von $19 \mathrm{~mm}$ gekürzt. Anschließend wurden die Wurzelkanäle mit Papierspitzen der ISO-Größe 15 getrocknet. Die Wurzeln wurden dann erneut im Mikro-CT für $1 \mathrm{~h} 11$ min bei einer Pixelauflösung von 10,5 $\mu \mathrm{m}$ unter $90 \mathrm{kV}$ Spannung mit $111 \mu \mathrm{A}$ Stromstärke, einem Rotationsabstand von $0,4^{\circ}$ und einer Rahmenmittelung von 3 eingescannt. Die Röntgenstrahlung wurde mit einem Al 0,5 + Cu 0,038 Filter gefiltert. Die Scans wurden mit Nrecon (Version 1.7.3.0) rekonstruiert. Dabei wurde bei jeder Wurzel post alignment und ring artifactsKorrektur individuell justiert sowie beam hardening auf $40 \%$ und smoothing auf Grad 3 eingestellt. Dabei entstanden pro Zahn zwischen 700-1200 Querschnitte im portable network graphics (PNG)-Format. 


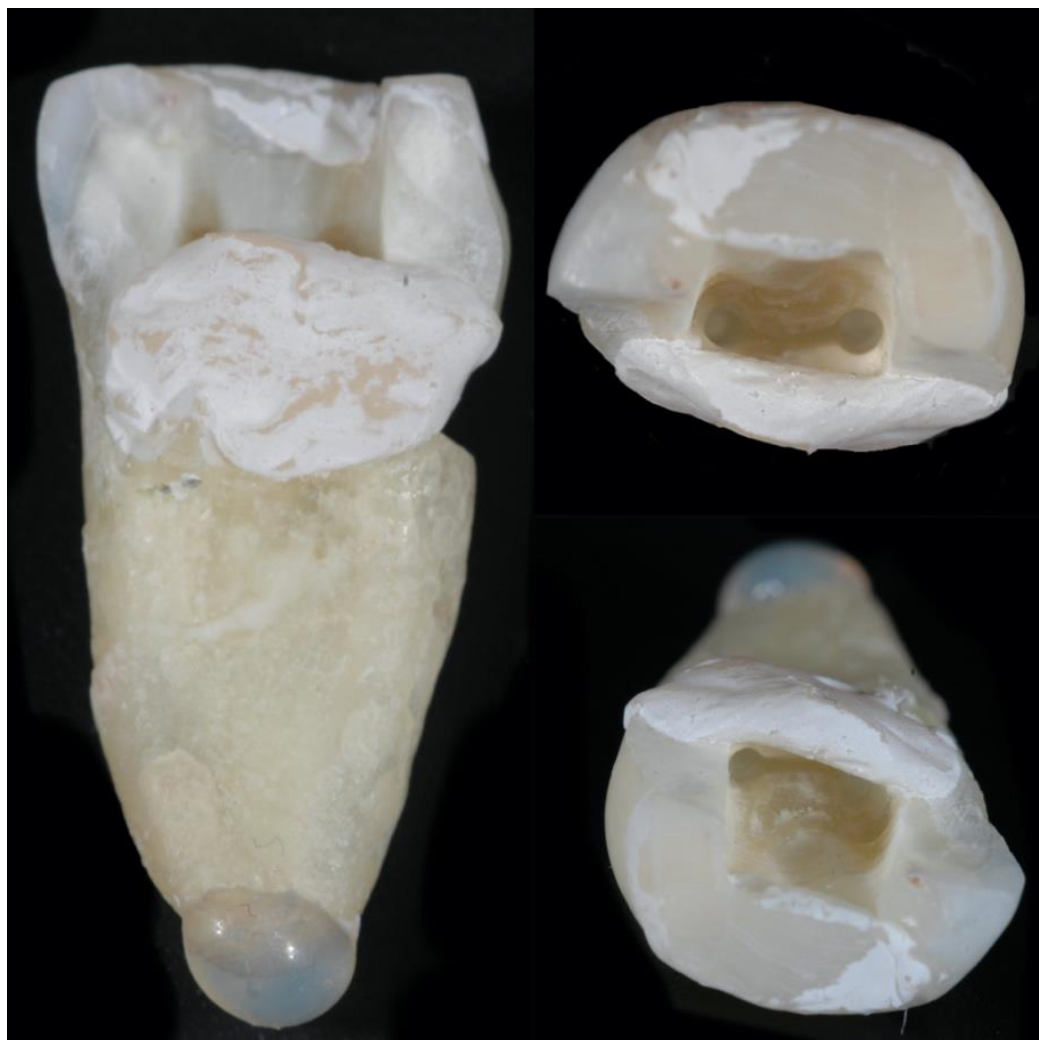

Abbildung 12: Mesiale Wurzel mit apikalem Klebeverschluss und Kompositwand zur Aufnahme der Spülflüssigkeit

\subsubsection{Präparation der Wurzelkanäle}

Die Präparation der bukkalen und lingualen Wurzelkanäle erfolgte mit Reciproc R25 NiTi-Instrumenten mit dem VDW Silver Motor auf eine standardisierte Arbeitslänge $(A L)$ von $18 \mathrm{~mm}$. Pro Kanal wurden mit dem Instrument jeweils vier Zyklen à drei Pickbewegungen durchgeführt. Nach jedem Zyklus wurde der Kanal mit $2 \mathrm{ml} 1 \%$ gen Natriumhypochlorit $(\mathrm{NaOCl})$ für eine Minute unter Verwendung einer 5-ml-Einwegspritze Endo-Eze Tip der Größe 30 gespült. Die Spülkanüle wurde dabei bis zur erreichten Präparationstiefe vorgeschoben, jedoch nicht weiter als $\mathrm{AL}$ minus $1 \mathrm{~mm}$. Im Anschluss daran wurde die Gängigkeit der Kanäle mit einem Reamer ISO-Größe 10 überprüft und das R25-Instrument erneut in den Kanal eingebracht. Mit jedem ReciprocInstrument wurden vier Kanäle präpariert. Die Trocknung erfolgte, wie vorher beschrieben, mit Papierspitzen der ISO-Größe 15. Die Wurzeln wurden nun erneut im Mikro-CT unter den zuvor beschriebenen Einstellungen gescannt und mit der Nrecon-Software (Version 1.7.3.0) rekonstruiert. 


\subsubsection{Bestimmung des Debrisvolumens}

Unter Zuhilfenahme der Software DataViewer (Version 1.5.2.4) wurden die präund postoperativen Scans einer Probe dreidimensional überlagert. Um dies zu standardisieren, wurde ein Probezahn fünfmal rekonstruiert, überlagert und der Messfehler berechnet. Es ergab sich eine Standardabweichung von 0,57 \%. Die Scans wurden anschließend in die Software CTAnalyzer (Version 1.17.7.2) importiert und das Kanalvolumen von der Furkation bis zum Apex definiert. Das Kanalvolumen des präoperativen Scans wurde als region of interest (ROI) festgelegt. Um das Dentin vom Kanalvolumen zu trennen, wurde ein thresholding durchgeführt und im Anschluss das Dentin in der Darstellung entfernt (Abbildung 13). Dabei wurden auch Artefakte, die kleiner als 50 Pixel im zweidimensionalen Bereich waren, ebenfalls entfernt. Das präoperative Kanalvolumen wurde nun mit dem postoperativen Scan überlagert.
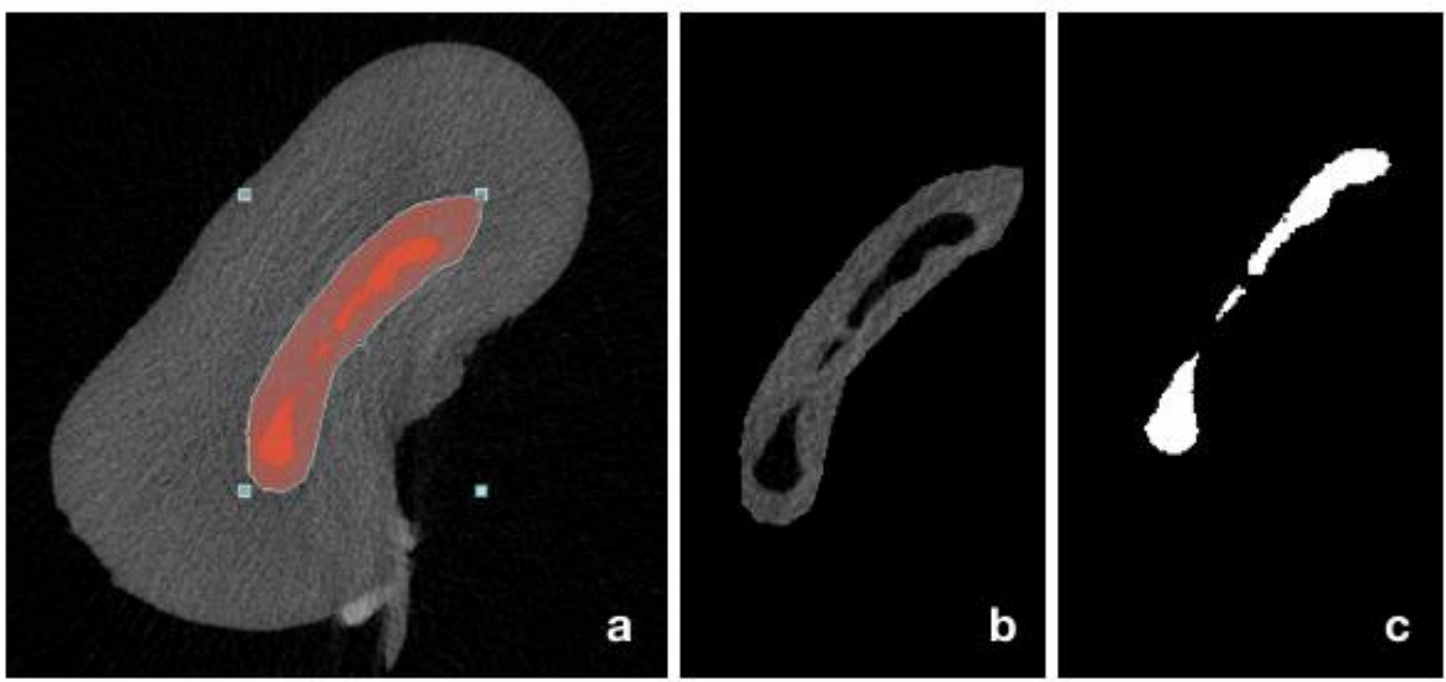

Abbildung 13: Micro-CT-Bildsequenzanalyse eines präoperativen Zahnes im axialen Schnitt (a) ROI (region of interest) rot makiert (b) seperate Darstellung des ROls (c) Durchführung des thresholding

Das Volumen des durch die Präparation entstandenen Debris wurde als röntgenopakes Material im Isthmusbereich definiert, das präoperativ nicht vorhanden war (Abbildung 14). Quantitativ wurde die Menge des Debris in $\mathrm{mm}^{3}$, die Kanaloberfläche in $\mathrm{mm}^{2}$ und das präoperative Kanalvolumen in $\mathrm{mm}^{3}$ ermittelt. Abschließend wurde der prozentuale Debrisanteil in Bezug auf das gesamte Volumen des Wurzelkanals berechnet. 

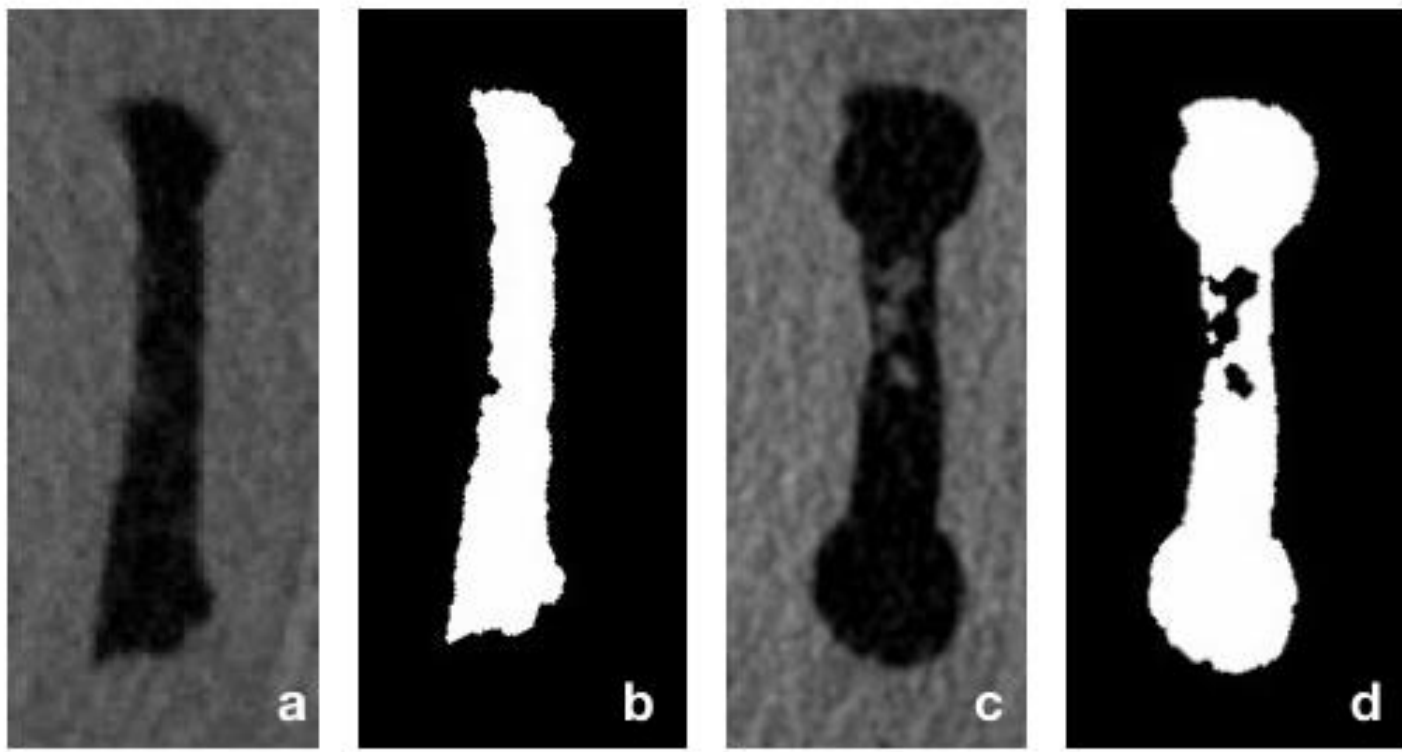

Abbildung 14: Mikro-CT-Bildsequenzen: Präoperativer Scan vor (a) und nach Binarisierung (b). Postoperativer Scan mit Debrisansammlung im Isthmus vor (c) und nach Binarisierung (d)

\subsubsection{Gruppeneinteilung}

Mithilfe des Kurskal-Wallis Test $(p<0,05)$ erfolgte die Aufteilung der 40 Proben in vier homogene Gruppen ( $n=10)$ entsprechend den in Tabelle 2 dargestellten Parametern. Dabei wurde die Kontrollgruppe mit der Handspülung (HD) im Vergleich zur Schallaktivierung mit EDDY (ED), Schallaktivierung mit EndoActivator (EA) und Ultraschallaktivierung (US) hinsichtlich der Reinigungswirkung im Isthmus untersucht.

Tabelle 2: Parameter zur Gruppeneinteilung mit jeweiligem $p$-Wert, Mittelwert \pm Standardabweichung von HD (Handspülung), ED (EDDY), EA (EndoActivator), US (Ultraschallaktivierung)

\begin{tabular}{lccccc}
\hline Gruppen & $\begin{array}{c}\text { Wurzel- } \\
\text { krümmungs- } \\
\text { winkel } \\
{\left[{ }^{\circ}\right]}\end{array}$ & $\begin{array}{c}\text { Wurzel- } \\
\text { krümmungs- } \\
\text { radius } \\
{[\mathrm{mm}]}\end{array}$ & $\begin{array}{c}\text { Kanal- } \\
\text { volumen }\end{array}$ & $\begin{array}{c}\text { Debris- } \\
\text { volumen }\end{array}$ & $\begin{array}{c}\text { Kanalober- } \\
\text { fläche }\end{array}$ \\
\hline HD & $19,14 \pm 5,47$ & $10,29 \pm 3,55$ & $4,04 \pm 1,85$ & $7,86 \pm 3,95$ & $56,90 \pm 20,64$ \\
\hline ED & $20,70 \pm 4,31$ & $9,71 \pm 2,00$ & $4,04 \pm 2,00$ & $7,88 \pm 3,96$ & $54,15 \pm 18,76$ \\
\hline EA & $20,87 \pm 3,71$ & $8,83 \pm 1,91$ & $4,44 \pm 1,31$ & $8,61 \pm 4,31$ & $65,23 \pm 24,15$ \\
US & $19,66 \pm 4,67$ & $9,99 \pm 1,84$ & $3,98 \pm 1,88$ & $7,18 \pm 3,59$ & $60,28 \pm 25,15$ \\
\hline & $p=0,883$ & $p=0,577$ & $p=0,827$ & $p=0,949$ & $p=0,825$ \\
\hline
\end{tabular}




\subsubsection{Hauptversuch}

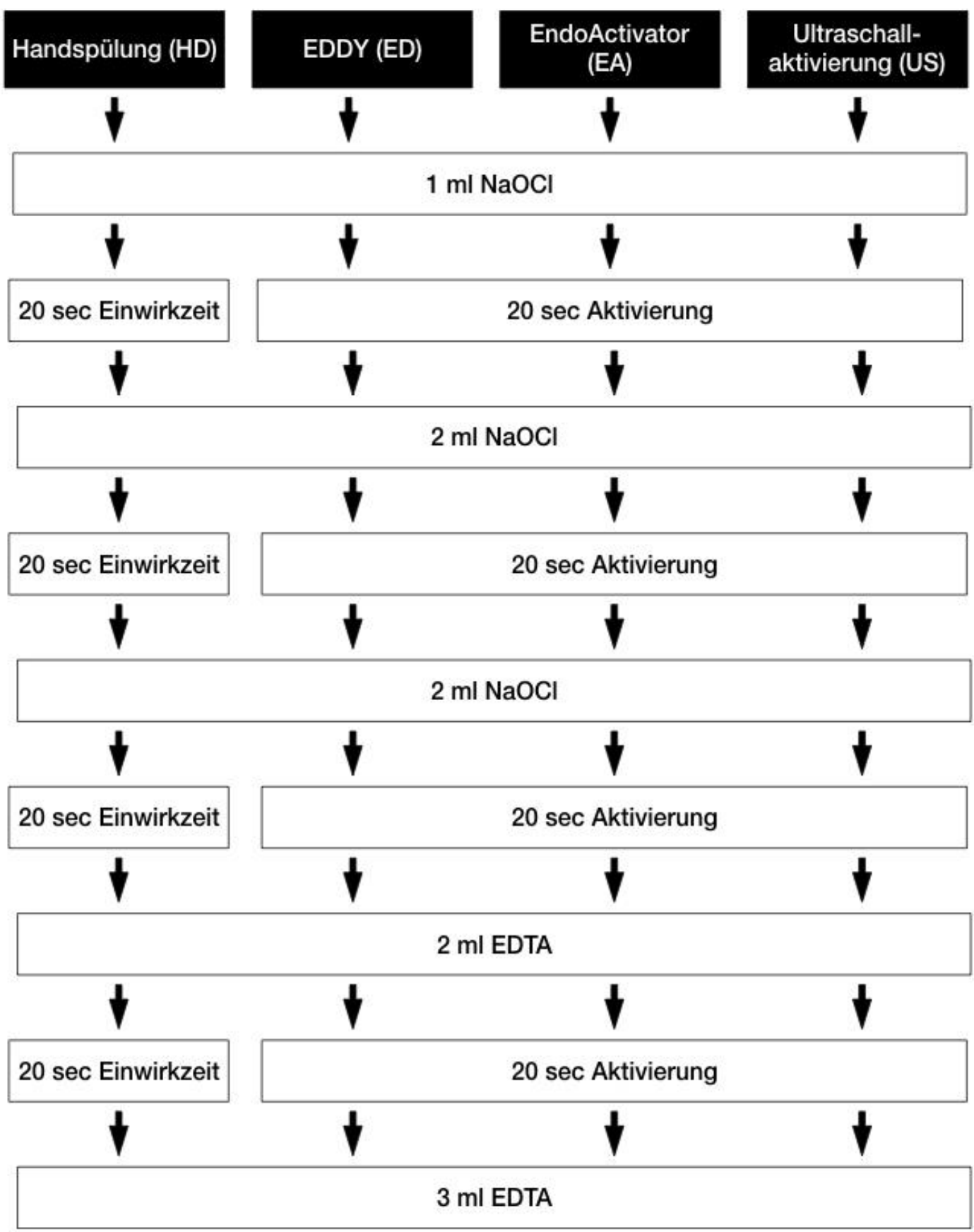

Abbildung 15: Spülprotokoll der experimentellen Gruppen: Handspülung (HD), EDDY (ED), EndoActivator (EA), Ultraschallaktivierung (US)

Das in Abbildung 15 dargestellte Spülprotokoll wurde pro Kanal durchgeführt. Als Spülflüssigkeiten wurden $\mathrm{NaOCl}(1 \%)$ und EDTA (15\%) verwendet, die jeweils mit einer $5 \mathrm{ml}$ Einwegspritze und einem Endo-Eze Tip der Größe 30 appliziert wurden. Die Ansätze für die Schall- bzw. Ultraschallaktivierung wurden jeweils auf $A L$ minus $2 \mathrm{~mm}$ in den Wurzelkanal inseriert. 


\section{Handspülung (HD) ( $n=10)$}

In dieser Kontrollgruppe erfolgte keine Aktivierung der Spülflüssigkeit, stattdessen wurde die Spülflüssigkeit für $20 \mathrm{sec}$ im Kanal belassen. Die Spülflüssigkeit wurde mit einem Endo-Eze Tip der Größe 30 appliziert.

\section{EDDY (ED) $(n=10)$}

Es erfolgte die Aktivierung der Spülflüssigkeit mit dem EDDY-Aufsatz für jeweils 20 sec. Dabei wurde das Sonic-Handstück auf Stufe 2 eingestellt, wodurch der EDDY mit einer Frequenz von $6000 \mathrm{~Hz}$ betrieben wurde.

\section{EndoActivator $(E A)(n=10)$}

Die Aktivierung der Spülflüssigkeit wurde mit dem EndoActivator-Handstück durchgeführt, das mit einem Activator Tip der Größe 15/.02 bestückt war. Die Frequenz lag bei $166 \mathrm{~Hz}$.

\section{Ultraschall (US) $(n=10)$}

Die Ultraschallaktivierung erfolgte mit dem IRRI S-Ansatz der Größe 25 und dem VDW Ultra-Gerät, wobei eine Intensität von $30 \%$ der maximalen Intensität eingestellt war.

Nachdem das in Abbildung 15 dargestellte Spülprotokoll bei jeweils beiden mesialen Kanälen abwechselnd durchgeführt worden war, erfolgte die Trocknung der Kanäle mit Papierspitzen der ISO-Größe 15. Abschließend wurde ein dritter Mikro-CT Scan der Proben, wie bereits zuvor beschrieben, durchgeführt und die Daten anschließend dreidimensional rekonstruiert.

Die Bestimmung des postoperativen Debrisvolumens wurde nach dem gleichen Prinzip wie zuvor durchgeführt. Dabei erfolgte die Überlagerung zwischen dem präoperative Scan und dem Postspül-Scan. Um den prozentualen Anteil der Reduzierung des Debris zu berechnen, wurde folgende Formel verwendet:

$$
\operatorname{Red}_{\text {Debris }}=\frac{V_{\text {postop }}-V_{\text {postspül }}}{V_{\text {postop }}} * 100
$$

$\operatorname{Red}_{\text {Debris }}:$ Prozentualer Anteil der Reduzierung des Debris

$V_{\text {postop }}$ : Debrisvolumen nach Präparation in $\mathrm{mm}^{3}$

$V_{\text {postspül }}$ Debrisvolumen nach Anwendung des jeweiligen Spülprotokolls in $\mathrm{mm}^{3}$

Abschließend wurde die Isthmusbreite aller Wurzeln an der schmalsten und breitesten Stelle bestimmt.

Die statistischen Analysen wurden mit der Software Statistica Version 11 durchgeführt. Die Überprüfung der Daten auf Normalverteilung erfolgte mit dem 
Quantil-Quantil Test. Da eine Normalverteilung vorlag, wurde eine nichtparametrische Varianzanalyse (ANOVA) durchgeführt. Das Signifikanzniveau wurde auf $\alpha=0,05$ festgelegt. Die grafische Darstellung der Ergebnisse erfolgte mit der gleichen Software. 


\section{$5 \quad$ Ergebnisse}

Die Isthmusbreiten aller Gruppen sind in Tabelle 3 verzeichnet. Dabei liegen die Mittelwerte der schmalsten Stelle zwischen 0,08 $\mathrm{mm}$ und 0,11 $\mathrm{mm}$. An der breitesten Stelle liegen die Mittelwerte zwischen $0,21 \mathrm{~mm}$ und $0,29 \mathrm{~mm}$. Es zeichnen sich keine signifikanten Unterschiede ab.

Tabelle 3: Isthmusbreiten der Proben unterteilt in die einzelnen Gruppen. HD (Handspülung), ED (EDDY), EA (EndoActivator), US (Ultraschallaktivierung)

\begin{tabular}{|l|l|l|l|l|l|l|}
\hline & \multicolumn{3}{|l|}{ Schmalste Isthmusbreite [mm] } & \multicolumn{3}{l|}{ Breiteste Isthmusbreite [mm] } \\
\hline Gruppe & Max & Min & Mittelwert & Max & Min & Mittelwert \\
\hline HD & 0,35 & 0,04 & 0,11 & 0,33 & 0,10 & 0,21 \\
\hline ED & 0,17 & 0,02 & 0,08 & 0,51 & 0,12 & 0,29 \\
\hline EA & 0,10 & 0,05 & 0,08 & 0,41 & 0,13 & 0,27 \\
\hline US & 0,17 & 0,05 & 0,10 & 0,41 & 0,14 & 0,25 \\
\hline
\end{tabular}

In allen vier Gruppen wurde keine signifikante Reduzierung des Debris festgestellt ( $p=0,208)$. Es bestand zwischen den Gruppen HD, ED, EA und US ebenfalls kein signifikanter Unterschied hinsichtlich der prozentualen Reduzierung des Debris. Somit konnte die Nullhypothese abgelehnt werden ( $p$ $>0,05)$.

Die Ergebnisse zeigen, dass die verschiedenen Techniken für die Aktivierung der Wurzelkanalspülung der Handspülung im Hinblick auf die Entfernung von Debris aus dem Isthmus nicht signifikant überlegen sind. Die Mittelwerte und Standardabweichungen der jeweiligen Spülungsaktivierungen sind in Tabelle 4 aufgeführt. Die dazugehörige Messspanne ist ebenfalls angegeben. 
Tabelle 4: Mittelwerte der einzelnen Gruppe \pm Standardabweichung. HD (Handspülung), ED (EDDY), EA (EndoActivator), US (Ultraschallaktivierung)

\begin{tabular}{|c|c|c|c|c|}
\hline \multirow[t]{2}{*}{ Gruppe } & \multirow{2}{*}{$\begin{array}{c}\text { Anzahl } \\
\text { der } \\
\text { Proben }\end{array}$} & \multicolumn{2}{|c|}{ Reduzierung von Debris [\%] } & \multirow[b]{2}{*}{ Max } \\
\hline & & Mittelwert \pm SD & Min & \\
\hline HD & 10 & $44,1 \pm 17,4$ & 16,00 & 72,73 \\
\hline ED & 10 & $56,8 \pm 24,1$ & 24,32 & 82,19 \\
\hline EA & 10 & $54,1 \pm 21,4$ & 18,52 & 87,88 \\
\hline US & 10 & $66,8 \pm 29,1$ & 13,04 & 93,33 \\
\hline
\end{tabular}

SD: Standardabweichung

Es zeigt sich, dass die Ultraschallaktivierung mit 66,8 \% $\pm 29,1 \%$ den höchsten Mittelwert besitzt. In dieser Gruppe wurde eine Debrisreduzierung bis zu 93,33\% erreicht. Im Vergleich zu den anderen Gruppen ist dies die größte Debrisreduzierung. Es wird deutlich, das keine Spülungsaktivierung in der Lage war, den Debris vollständig zu entfernen. In Abbildung 16 werden die genannten Ergebnisse in einem Box-Plot-Diagramm grafisch dargestellt. Hier zeigt sich deutlich, dass die Spanne zwischen Minimum und Maximum bei allen Gruppen groß ist.

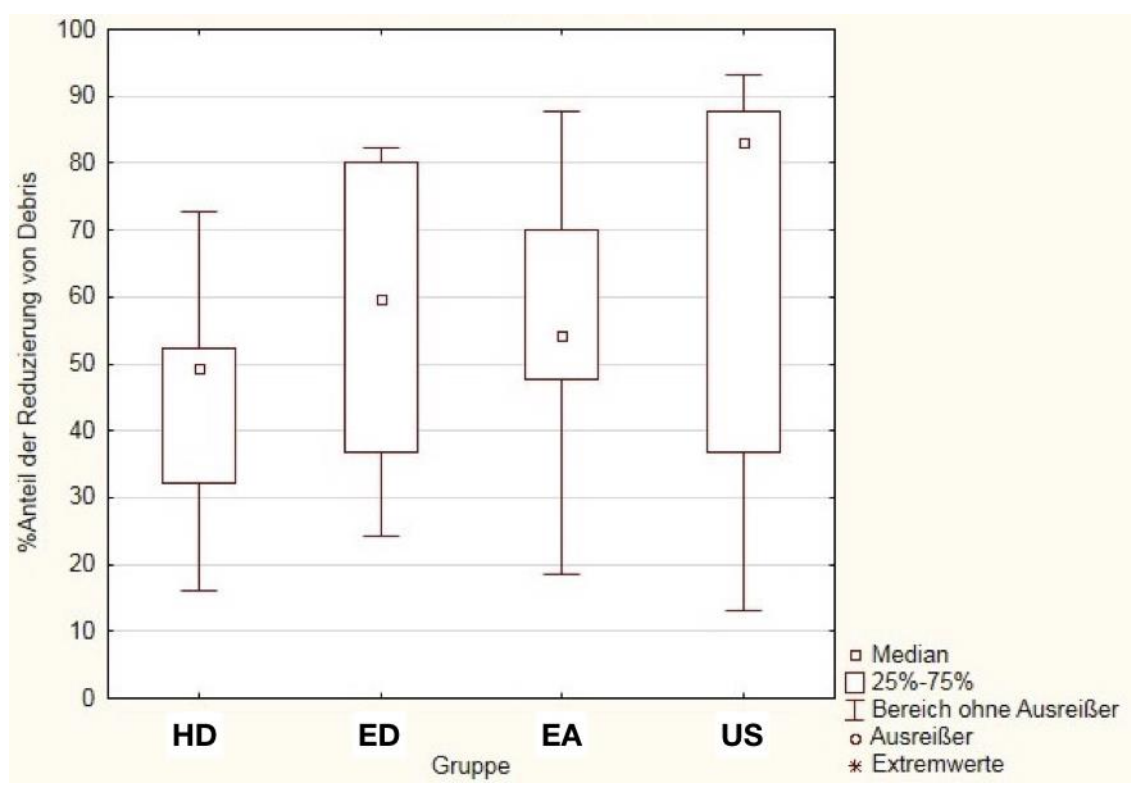

Abbildung 16: Box-Plot-Diagramm zur Darstellung der Verteilung vom prozentualen Anteil der Reduzierung von Debris. Handspülung (HD), EDDY (ED), EndoActivator (EA), Ultraschallaktivierung (US) 
In Abbildung 17 zeigen repräsentative dreidimensionale Modelle die Verteilung des Debris im Wurzelkanal nach Präparation und Verwendung des jeweiligen Spülprotokolls.

HD
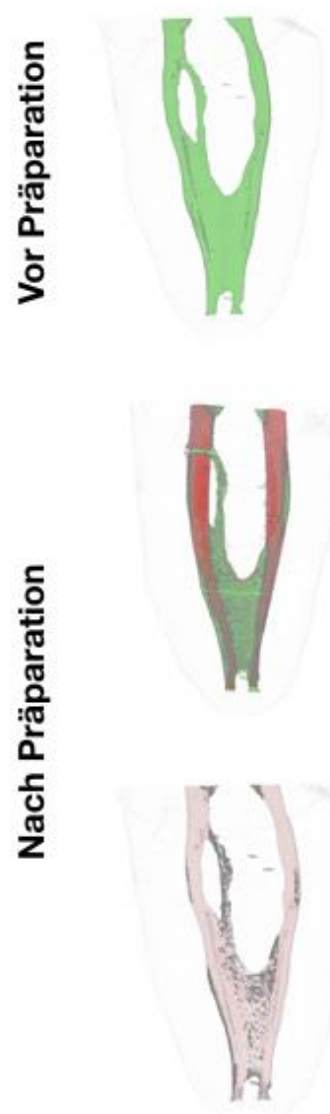

을
ED
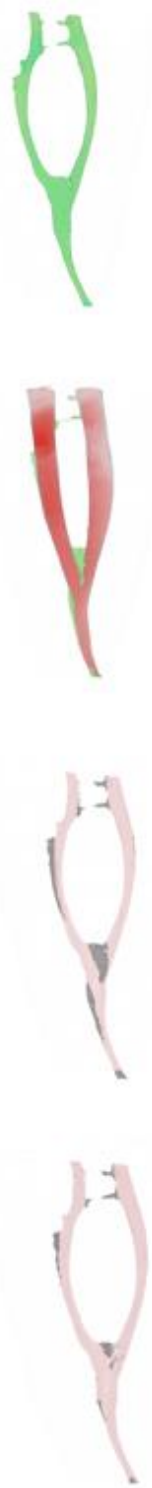

EA

US
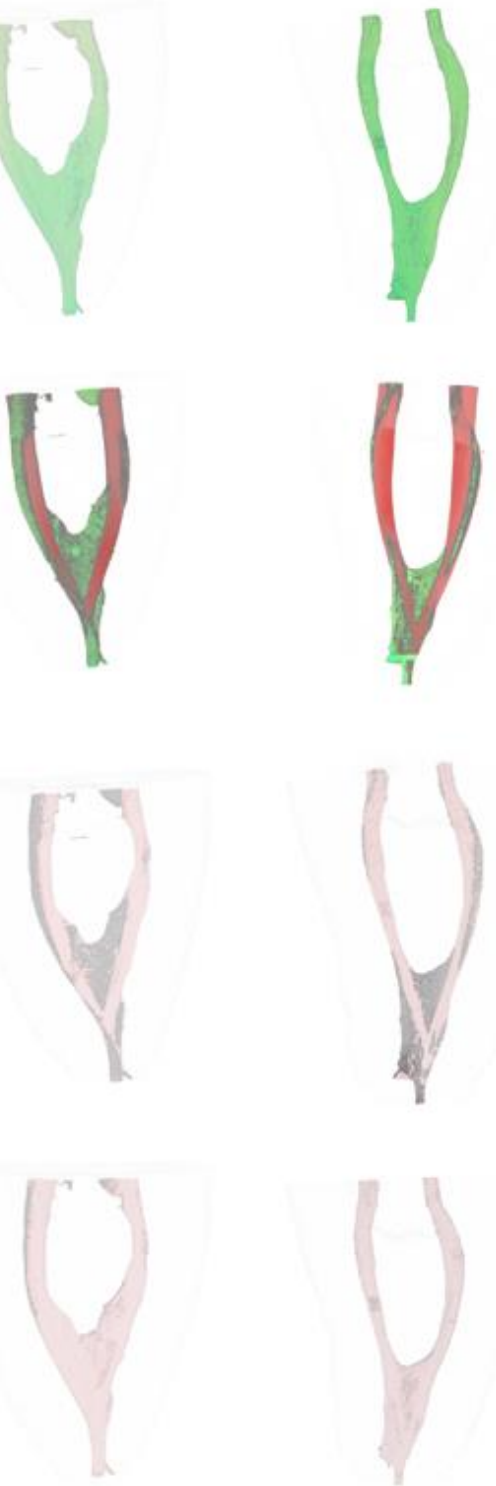

Abbildung 17: Mesiale Ansicht repräsentativer 3D-Rekonstruktionen des Kanalsystems von vier Unterkiefer-Molaren vor (grün) und nach (rot) Präparation mit dem Reciproc-System und nach Abschlussspülprotokoll mit Handspülung (HD), EDDY (ED), EndoActivator (EA) und Ultraschallaktivierung (US). Der Debris ist in grau dargestellt. 


\section{Diskussion}

\subsection{Diskussion der Methode}

Ziel dieser Studie war es, die Effektivität verschiedener Techniken für die Aktivierung der Wurzelkanalspülung hinsichtlich der Entfernung von Debris aus Isthmen unterer Molaren im Vergleich zur Handspülung zu überprüfen. Die Durchführung dieser Untersuchung orientierte sich an den Studien von Leoni et al. (2016), Keleş et al. (2016), Paqué et al. (2009a, 2011) und Freire et al. (2015). Die Auswertung des Debris im Wurzelkanal erfolgte anhand einer dreidimensionalen Darstellung mittels Mikro-CT.

\subsubsection{Vorbereitung der Zähne}

Als Probekörper wurden ausschließlich menschliche Unterkiefermolaren ausgewählt. Ein wichtiges Auswahlkriterium dabei war, dass die Wurzelkanäle der mesialen Wurzel zuerst getrennt verliefen und sich im apikalen Drittel vereinigten (Vertucci-Klasse II). Der hierbei entstehende Isthmus zwischen den beiden Wurzelkanälen verlief somit nicht durchgängig, wenn man die gesamte Wurzelkanallänge betrachtet. Es war das Ziel, eine präparationsbedingte Ansammlung von Debris in diesen Isthmen zu produzieren, um anschließend verschiedene Methoden für die Aktivierung der Spülflüssigkeit in Hinblick auf die Entfernung dieses Debris zu untersuchen.

Keleş et al. (2016) nahmen ebenfalls Wurzelkanäle mit einer Vertucci-Klasse II, wohingegen Leoni et al. (2016) Wurzelkanäle mit einem durchgängigen Isthmus auf gesamter Länge (Vertucci-Klasse I) bevorzugten. In der vorliegenden Untersuchung wurden ausschließlich Wurzeln mit einer Isthmuslänge von mindestens $2 \mathrm{~mm}$ in koronal-apikaler Richtung verwendet, um die anatomische Variationen der Wurzeln weitestgehend zu standardisieren (Paqué et al. 2011). Es muss allerdings berücksichtigt werden, dass jeder Isthmus in seiner dreidimensionalen Ausdehnung variiert und diese niemals als identisch anzusehen sind. Nur standardisierte Plastikblöcke schaffen identische Voraussetzungen für eine Untersuchung, allerdings mit der Einschränkung, dass diese nicht die komplexe Wurzelkanalanatomie widerspiegeln. Die poröse Struktur des Dentins mit den Tubuli, die Benetzbarkeit des Dentins sowie Ramifikationen, Einbuchtungen oder Seitenkanäle werden dabei nicht berücksichtigt und entsprechen somit nicht dem natürlichen Wurzelkanalsystem (Goode et al. 2013; Lee et al. 2004a; Malki et al. 2012). 
In der vorliegenden Studie wurden für eine bessere Standardisierung der Proben ausschließlich Wurzeln mit einer moderaten Wurzelkanalkrümmung von $10^{\circ}$ bis $25^{\circ}$ und einem -radius zwischen $5,5 \mathrm{~mm}$ und $16,5 \mathrm{~mm}$ ausgewählt. Die Festlegung dieser anatomischen Merkmale erfolgte anhand eines Röntgenbildes in bukko-lingualer Richtung mittels der Methoden von Schneider (1971) und Schäfer et al. (2002). Die Beurteilung der Lage der zu bestimmenden Punkte wurde nur von einem Untersucher durchgeführt, um ein einheitliches Vorgehen zu gewährleisten. Es handelt sich dennoch um eine subjektive Beurteilung der Wurzelkanalkrümmung, weil die Auswertung individuell geschieht und Abweichungen zu anderen Untersuchern möglich sind.

Auch andere Autoren verwerteten ausschließlich Zähne mit moderat gekrümmten Wurzelkanälen (De-Deus et al. 2014; Keleş et al. 2016; Leoni et al. 2016). In der hier vorliegenden Studie wurde eine moderate Wurzelkanalkrümmung ausgewählt, da starke Krümmungen das Risiko von Instrumentenfrakturen oder Wurzelkanalperforationen erhöhen (Card et al. 2002). Bei stärkerer Wurzelkanalkrümmung und engerem Krümmungsradius steigt das Risiko eines iatrogenen Präparationsfehlers erheblich (Lambrianidis 2009).

Ein weiterer Aspekt betrifft die Verwendung extrahierter Zähne ohne umliegendes periapikales Gewebe. Da diese In-vitro-Studie an Zähnen außerhalb der Mundhöhle durchgeführt wurde, ergibt sich, dass die Zutrittsöffnung des Nervens an der Wurzelspitze unverschlossen ist. Um apikal eine Extrusion der Spülflüssigkeit zu vermeiden und so ein geschlossenes System zu simulieren (Keleş et al. 2016), wurden die apikalen Foramina, ähnlich wie in früheren Untersuchungen, mit Heißkleber versiegelt (De-Deus et al. 2013; Keleş et al. 2016; Leoni et al. 2016). Andere Autoren verzichteten allerdings auf einen apikalen Verschluss der Wurzelspitze (Paqué et al. 2011).

Anschließend erfolgte in dieser Studie die einheitliche Kürzung der Zähne auf $19 \mathrm{~mm}$. Dies entspricht zwar nicht den klinischen Gegebenheiten, ermöglicht aber eine weitere Standardisierung der Proben.

Nach Separierung der Wurzeln wurde die offene Seite des Pulpenkavums wieder hergestellt, indem eine dünne Kompositschicht an der Trennstelle der Wurzel adhäsiv befestigt und so ein Reservoir für die Spülflüssigkeit geschaffen wurde (Susin et al. 2010). Während der Abschlussspülung wurde zuerst die Spülflüssigkeit mithilfe einer herkömmlichen Spritze und einer Kanüle in die Kanäle eingebracht und anschließend aktiviert (Intermittent flush-Technik) (Jiang et al. 2012). 
Insgesamt wurden pro Wurzelkanal $8 \mathrm{ml} \mathrm{NaOCl}$ während der Präparation appliziert. In Vorversuchen war festgestellt worden, dass dieses Volumen das Risiko einer Verblockung des Kanals während der Präparation verminderte und dennoch eine ausreichende Akkumulation von Debris im Isthmus ermöglichte. In der vorliegenden Studie wurde so eine durchschnittliche Debrisakkumulation im Isthmus von 7,9 Vol.-\% durch die Präparation erreicht. Eine Präparation der Wurzelkanäle ohne Verwendung von Spülflüssigkeit erzielte in einer vergleichbaren Untersuchung eine durchschnittliche Menge an Debris von 29,2 \pm 14,5 Vol.-\% (Paqué et al. 2009a), wohingegen andere Autoren insgesamt mit $20 \mathrm{ml} \mathrm{NaOCl}$ pro Kanal spülten und eine durchschnittliche Debrismenge zwischen 1,86 Vol.-\% und 2,01 Vol.-\% erzielten (Keleş et al. 2016).

Da in früheren Studien moderat gekrümmte Wurzelkanäle bis Größe 25 präpariert wurden (De-Deus et al. 2014; Freire et al. 2015; Keleş et al. 2016; Leoni et al. 2016), wurde in der vorliegenden Studie aus Gründen der Vergleichbarkeit die gleiche Präparationsgröße gewählt. In anderen Studien, die keine Angaben zur Wurzelkrümmung festlegten, wurde eine apikale Erweiterung bis zur Größe 30 durchgeführt (Paqué et al. 2011). Obwohl eine größere apikale Erweiterung die Effektivität der Spülung steigert (Card et al. 2002; Jeon et al. 2014), erhöht sich auch gleichzeitig das Risiko einer Perforation oder einer iatrogen verursachten Stufe (Albrecht et al. 2004; Card et al. 2002). Eine apikale Erweiterung des Wurzelkanals von mehr als Größe 25 erhöht zwar die Spülwirkung, es ist jedoch wichtiger, einen angemessenen Raum zwischen Kanalwand und Spülkanüle zu gewährleisten und so einen koronalen Abfluss der Spülflüssigkeit zu ermöglichen (Boutsioukis et al. 2010). Das für die Präparation verwendete R25-Instrument weist auf den ersten $3 \mathrm{~mm}$ eine Konizität von $8 \%$ und anschließend eine Konizität von $4 \%$ auf (Keleş et al. 2016; Kiefner 2015). Bei einer Insertion der Spülkanüle auf AL minus $2 \mathrm{~mm}$ weist der Wurzelkanal auf dieser Höhe einen Durchmesser von 0,41 mm auf, wodurch die Spülkanüle der Größe 30 mit einem apikalen Durchmesser von $0,3 \mathrm{~mm}$ zirkulär genügend Abstand zur Wurzelkanalwand besitzt.

\subsubsection{Gruppeneinteilung}

Die Gruppeneinteilung erfolgte anhand mehrerer anatomischer Parameter, um möglichst standardisierte Voraussetzungen für die Versuche zu schaffen. Das präoperative Wurzelkanalvolumen, der Wurzelkanalkrümmungswinkel und -radius, die Wurzelkanaloberfläche und das postoperative Debrisvolumen wurden dabei als Parameter gewählt. Daraufhin wurden die Wurzeln mittels Kruskal-Wallis-Test anhand der aufgezählten Parameter möglichst homogen in 
vier Gruppen à zehn Zähnen verteilt (Keleş et al. 2016; Leoni et al. 2016). Keleş et al. (2016) bezogen zusätzlich die Oberfläche, Länge und das Volumen des Isthmus mit ein. Der Vorteil der Homogenisierung der Gruppen liegt in einer verbesserten Standardisierung der Probekörper und reduziert die anatomische Variabilität zwischen den Prüfkörpern (Silva et al. 2019; Versiani et al. 2013).

Die Gruppengröße wurde ähnlich wie in früheren Studien (Keleş et al. 2016; Leoni et al. 2016; Verstraeten et al. 2017) auf zehn Zähne festgelegt. Eine weitere Studie basierte auf einer erhöhten Anzahl von zwanzig Zähnen pro Gruppe (Paqué et al. 2011).

Die Insertion der Schall- und Ultraschall-Ansätze erfolgte auf AL minus $2 \mathrm{~mm}$. Dabei wurde die Spülflüssigkeit bei allen Gruppen in vier Zyklen á $20 \mathrm{sec}$ aktiviert. In der Kontrollgruppe „Handspülung“ erfolgte keine Aktivierung. Die Spülflüssigkeit wurde dort jeweils $20 \mathrm{sec}$ im Wurzelkanal belassen. Die Aktivierung der Spülflüssigkeit wurde in anderen Studien in nur drei Zyklen à $20 \mathrm{sec}$ durchgeführt (Leoni et al. 2016; Schiavotelo et al. 2017), wohingegen auch Aktivierungszeiten von $90 \mathrm{sec}$ (Freire et al. 2015) oder insgesamt $240 \mathrm{sec}$ durchgeführt wurden (Keleş et al. 2016). Da jedoch kein signifikanter Unterschied in der Effektivität der Debrisentfernung mittels Ultraschallaktivierung bei deiner Dauer von $30 \mathrm{sec}$ bzw. $60 \mathrm{sec}$ festgestellt wurde (Sabins et al. 2003), wurde in der vorliegenden Untersuchung eine Aktivierungszeit von insgesamt 80 sec gewählt.

Für die Schallaktivierung mit dem EndoActivator wurde die kleinste Größe der Aktivierungsspitze ausgesucht (Größe 15/.02). Die Verwendung des mittelgroßen Ansatzes (25/.04) hätte bei einem Wurzelkanal mit einer apikalen Größe von 25 möglicherweise zu einem Verklemmen der Spitze und zu einer eingeschränkten Effektivität der Aktivierung geführt.

Die Ultraschallaktivierung gilt als etablierte Methode zu Aktivierung der Spülflüssigkeit in der Endodontologie (Dutner et al. 2012) und findet auch deshalb Anwendung in der vorliegenden Untersuchung. Ein freies Schwingen der Feile im Wurzelkanal ist wichtig, um eine größtmögliche akustische Strömung zu erzeugen und einen unkontrollierten Abtrag von Dentin zu vermeiden (Retsas et al. 2016). Die Schwingung der Feile kann in gekrümmten Wurzelkanälen durch den frühzeitigen Kontakt mit den Kanalwänden gedämpft werden (Amato et al. 2011; Rödig et al. 2010)

\subsubsection{Evaluierung und Auswertung des Debris}

Das Ziel der meisten Studien zur Spülungsaktivierung ist es, das Ausmaß der Reduzierung von präparationsbedingtem Debris zu untersuchen. Dabei gibt es 
unterschiedliche Verfahren zur Darstellung und Berechnung des verbliebenen Debris im Wurzelkanalsystem. Eine bewährte Methode ist die Auswertung mithilfe eines Mikroskops. Dabei wird künstlich hergestellter Debris in vorpräparierte Vertiefungen gespaltener Zähne appliziert, die Zahnhälften adaptiert und nach Ultraschallaktivierung der in den Vertiefungen verbliebene Debris mithilfe des Stereomikroskops ausgewertet (Lee et al. 2004b). Die Vertiefungen sind zwar standardisiert, aber sie spiegeln nicht die Komplexität der Wurzelkanalanatomie wider. In anderen Studien wurden die Zähne präpariert, der Debris nach einem Spülprotokoll mit unterschiedlichen Aktivierungen entfernt und abschließend der zurückgebliebene Debris im Elektronenmikroskop beurteilt (Rödig et al. 2010; Urban et al. 2017). Dabei gibt es verschiedene Score-Systeme, mit deren Hilfe der verbliebene Debris bewertet wird (Hülsmann et al. 1997). Diese Evaluierung ist immer subjektiv und stark vom Untersucher abhängig (De-Deus et al. 2011). Zusätzlich muss berücksichtigt werden, dass ein Durchtrennen der Wurzeln zu einer Veränderung des Debrisvolumens führen kann.

Mithilfe des Mikro-CTs ist eine exakte und objektive Berechnung des Debrisvolumens im Wurzelkanalsystem möglich (Paqué et al. 2009a). Ein weiterer Vorteil liegt darin, dass die Proben einen zerstörungsfreien Analyseprozess durchlaufen und eine Bestimmung des Debrisvolumens nach der Präparation ohne Längsspaltung der Wurzeln erfolgt. Nach Anwendung der verschiedenen Wurzelkanalspültechniken wird erneut das Debrisvolumen ermittelt und die prozentuale Reduktion berechnet. Dieses Vorgehen wird durch die Überlagerung prä- und postoperativer Mikro-CT-Scans unterstützt. Dabei muss allerdings berücksichtigt werden, dass niemals eine exakte Repositionierung der beiden Scans gelingt. Paqué et al. (2009a) beschrieben einen Fehler bei der Überlagerung des prä- und postoperativen Scans, der eine Abweichung von ungefähr einem Voxel entspricht. Ein Voxel wird in der Computergrafik in einem dreidimensionalen Bild als ein Gitterpunkt definiert, der in einem zweidimensionalen Bild einem Pixel entspricht. Weitere Studien bestätigten diesen Überlagerungsfehler (De-Deus et al. 2014; Paqué et al. 2011; Paqué et al. 2012). Andere Autoren gaben allerdings keinen Fehler bei der Überlagerung prä- und postoperativer Mikro-CT-Aufnahmen an, verwendeten aber auch ein anderes Computerprogramm zur Analyse des verbliebenen Debris (Keleş et al. 2016; Leoni et al. 2016).

Eine weitere Fehlerquelle sind Artefakte, die während eines Scanvorgangs entstehen und Unregelmäßigkeiten im entstandenen Bild widerspiegeln. Diese Artefakte können zum Beispiel durch Erschütterung während des Scanvorgangs entstehen. In der vorliegenden Studie wurden die Zähne mit 
Schaumstoff im Objektträger stabilisiert, um diese Erschütterungen während des einstündigen Scans zu minimieren. Zusätzlich können Streuungen von röntgenopaken Materialien wie Komposit oder Amalgamsplitter, die während der Präparation von Zähnen mit Amalgamfüllungen entstehen, auftreten.

Die Bestimmung des Debris gelingt, indem der präoperative Scan mithilfe der Software CTAnalyzer mit dem postoperativen Scan überlagert und analysiert wird. Als Debris wird das Material bezeichnet, das im postoperativen Scan röntgenopak sichtbar wird und das im präoperativen Scan zuvor nicht vorhanden war (De-Deus et al. 2014; Paqué et al. 2009a; Robinson et al. 2012). Die richtige Einstellung der Grauwerte im Histogramm während der Analyse des Debris ist wichtig, um im dargestellten Bild eine Grenze zwischen Dentin und Luft festzulegen. In der vorliegenden Studie wurde eine Grauwert-Spanne von 0-40 ausgewählt. Es folgte die dreidimensionale Darstellung der Ergebnisse mithilfe der Software CTVox.

\subsection{Diskussion der Ergebnisse}

Bei keiner der untersuchten Spülmethoden wurde eine vollständige Entfernung des Debris aus dem Isthmus unterer Molaren festgestellt. Dies wird durch andere Studien mit einem ähnlichen Versuchsaufbau bestätigt (De-Deus et al. 2014; Freire et al. 2015; Keleş et al. 2016; Leoni et al. 2016; Paqué et al. 2011). Zusätzlich lag kein signifikanter Unterschied hinsichtlich der Entfernung des Debris zwischen den einzelnen Gruppen vor.

Durch die maschinelle Präparation wurde ein durchschnittliches Debrisvolumen von $7,9 \%$ erreicht, das somit in dem Bereich $(3,4 \%$ - 10,1 \%) früherer Studien liegt (Freire et al. 2015; Paqué et al. 2011, 2012; Verstraeten et al. 2017). In einer weiteren Untersuchung wurde mit durchschnittlich 0,23\% $\%$ 5,65\% deutlich weniger Debris durch die Präparation mit dem Reciproc R25Instrument produziert (Keleş et al. 2016). Allerdings bezog sich dieses Debrisvolumen auf das postoperative Wurzelkanalvolumen, das naturgemäß größer als das präoperative Wurzelkanalvolumen ist (Keleş et al. 2016). Ein weiterer Aspekt ist die Verwendung eines deutlich höheren Spülvolumens von $30 \mathrm{ml}$ pro Wurzelkanal (Keleş et al. 2016), während bei vollständigem Verzicht auf eine Spülung während der Präparation ein durchschnittliches postoperatives Debrisvolumen von 29,2 Vol.-\% erreicht wurde (Paqué et al. 2009a).

In der vorliegenden Studie diente die konventionelle Handspülung als Kontrollgruppe, da diese Spülmethode in der Endodontologie am weitesten verbreitet ist. Mit dieser Spülmethode wurde eine durchschnittliche Reduktion 
des Debris von 44,1 \% erreicht, ähnlich wie in einer vergleichbaren Studie, in der die Handspülung eine durchschnittliche Reduktion des Debris von 45,7\% erzielte (Leoni et al. 2016). Dabei gilt es zu berücksichtigen, dass in der Studie von Leoni et al. (2016) nur mit insgesamt 5,5 ml NaOCl pro Wurzelkanal gespült wurde. Das in der vorliegenden Studie verwendete Volumen von Spülflüssigkeit war beinahe doppelt so hoch, da mit jeweils $5 \mathrm{ml} \mathrm{NaOCl}$ und EDTA gespült wurde. Ein signifikanter Effekt von EDTA wurde bei der Handspülung unter Verwendung von $5 \mathrm{ml}$ pro Wurzelkanal mit einer Debrisreduzierung von 6,9 Vol.- $\% \pm 4,2$ Vol.- $\%$ auf 4,9 Vol.-\% \pm 3,6 Vol.-\% erreicht (Paqué et al. 2011). Dennoch verblieb mindestens die Hälfte des Debris im Wurzelkanalsystem (Paqué et al. 2011). Die Ursache für die unzureichende Reinigungswirkung der konventionellen Handspülung kann auf die Eindringtiefe der Nadel auf $2 \mathrm{~mm}$ vor $\mathrm{AL}$ zurückgeführt werden, da dies einen wesentlichen Faktor für die Wirksamkeit der Spüllösung darstellt (Abou-Rass und Piccinino 1982; Ram 1977). Eine Mikro-CT-Studie unterstützt diese These, da sie einen signifikanten Einfluss der Eindringtiefe der Spülkanüle in Bezug auf die Reduzierung des Debris aus dem Isthmus mesialer Wurzeln unterer Molaren zeigte (Perez et al. 2016). Es wurde dabei eine dreifach höhere Effektivität hinsichtlich der Entfernung von Debris erzielt bei einer Applikation der Spüllösung auf AL minus $1 \mathrm{~mm}$ anstatt auf $\mathrm{AL}$ minus $5 \mathrm{~mm}$ (Perez et al. 2016). Im Allgemeinen wurde jedoch vielfach festgestellt, dass die Handspülung bei komplexen anatomischen Strukturen im Wurzelkanalsystem eine unzureichende Reinigungswirkung entfaltet (Leoni et al. 2016; Paqué et al. 2009b; Ram 1977).

Laut derzeitigem Studienstand wurden bislang nur zwei Mikro-CT-Studien durchgeführt, die einen Vergleich zwischen konventioneller Handspülung und Ultraschallaktivierung in Bezug auf die Debrisreduktion vorgenommen haben (Leoni et al. 2016; Paqué et al. 2011). In beiden Studien wurde eine signifikant bessere Reduzierung des Debris mit der Ultraschallaktivierung im Vergleich zur Handspülung erreicht. Eine ultraschallaktivierte Spülung mit $\mathrm{NaOCl}$ und EDTA reduzierte den Debris um 50,8 \% \pm 18,7 \% (Paqué et al. 2011), was durch die Ergebnisse der vorliegenden Studie bestätigt wird (66,8 \% $\pm 29,1 \%)$. Eine deutlich effektivere Debrisreduktion nach Ultraschallaktivierung von 94,1 \% \pm $6,8 \%$ wurde ebenfalls beschrieben (Leoni et al. 2016) und mit der unterschiedlichen Konfiguration der Isthmen und dem unterschiedlichen Präparations- und Spülprotokoll begründet. Diese Autoren verwendeten Wurzelkanäle mit einem durchgängigen Isthmus (Vertucci-Klasse I), wodurch möglicherweise eine bessere Penetration der Spülflüssigkeit in den Isthmus erreicht wurde (Leoni et al. 2016). Weiterhin wurde eine Ultraschallfeile der Größe 20 verwendet (Leoni et al. 2016), wodurch die Möglichkeit besteht, dass 
die Ultraschallspitze zirkulär mehr Abstand zum Wurzelkanaldentin hatte. Frühzeitiger Wurzelkanalwandkontakt und eine starke Wurzelkanalkrümmung können die Schwingungen der Ultraschallspitze dämpfen und somit ihre Effektivität mindern (Adcock et al. 2011; Boutsioukis et al. 2013).

In einer weiteren Mikro-CT-Studie an Unterkiefermolaren mit einer Wurzelkanalkrümmung von $25^{\circ}-35^{\circ}$ wurde ebenfalls eine Ultraschallfeile der ISO-Größe 20 bei einer Präparationsgröße von 25 gewählt und für $3 \times 30 \mathrm{sec}$ aktiviert (Freire et al. 2015). Dabei wurde eine mit der vorliegenden Studie vergleichbare Debrisreduzierung von 55,55 \% $\pm 21,91 \%$ erreicht (Freire et al. 2015). Es wird deutlich, dass die Effektivität der Ultraschallaktivierung von mehreren Faktoren wie Größe der Feile, Wurzelkanalkrümmung, Wurzelkanalquerschnitt, Isthmusbreite, Aktivierungsdauer und Insertionstiefe der Ultraschallfeile abhängig ist.

Eine Mikro-CT-Studie zur Entfernung von Debris aus dem Isthmus unterer Molaren mittels Schallaktivierung liegt derzeit nicht vor. Der EDDY erzielte in der vorliegenden Studie eine durchschnittliche Reduktion des Debris von $55,8 \% \pm 24,1 \%$, wobei die große Standardabweichung auffällt. Bei sechs Proben wurde mehr als $50 \%$ des Debris aus dem Isthmus entfernt, wohingegen bei den vier weiteren Proben eine Reduktion des Debris zwischen $24,32 \%$ und $40 \%$ erzielt wurde. Diese hohe Standardabweichung ist vermutlich auf die variable Wurzelkanalanatomie zurückzuführen. Trotz einer möglichst umfassenden Standardisierung der Proben anhand von Wurzelkanalkrümmung und -radius, Debrisvolumen, Wurzelkanalvolumen sowie -oberfläche und einer einheitlichen Isthmuslänge von 2 mm (Paqué et al. 2011), weist jeder Zahn eine individuelle Wurzelkanalanatomie auf. Insgesamt lag kein signifikanter Unterschied zu den anderen untersuchten Spülmethoden vor.

Der EndoActivator erreichte mit einer durchschnittlichen Reduktion des Debris von $54,1 \% \pm 21,4 \%$ in der vorliegenden Studie vergleichbare Ergebnisse wie die Schallaktivierung mit dem EDDY. Bei sechs Wurzeln wurde eine Debrisreduzierung von mehr als $50 \%$ erzielt. Es liegen auch hier keine statistisch signifikanten Unterschiede, weder im Vergleich zu den anderen Aktivierungstechniken noch zur Handspülung vor. Dies lässt sich ebenfalls mit der Variabilität der Wurzelkanalanatomie begründen.

In einer elektronenmikroskopischen Studie zur Debrisreduktion, bei der die Sauberkeit des gesamten Wurzelkanals bewertet wurde, zeigte der EA ebenfalls keine signifikanten Unterschiede im Vergleich zur Handspülung (Rödig et al. 2010). Die Aktivierung für $3 \times 30 \mathrm{sec}$ mit EDDY, EndoActivator und Ultraschall zeigte im Hinblick auf die Debrisentfernung signifikant bessere 
Ergebnisse als die Handspülung (Urban et al. 2017). Dabei wurden Prämolaren hinsichtlich der Debrisentfernung aus dem gesamten Wurzelkanalsystem mithilfe eines Elektronenmikroskops untersucht (Urban et al. 2017). Da sich somit der Versuchsaufbau deutlich unterscheidet (Urban et al. 2017), entfällt auch hier ein genauer Vergleich zur vorliegenden Studie.

In einer Meta-Analyse zur Effektivität von schall- und ultraschallgestützter Spülungsaktivierung hinsichtlich der Entfernung von Debris und Schmierschicht, belegte im Vergleich zur Handspülung eine signifikante Verbesserung (Virdee et al. 2018). Ein Vergleich ist aber nur eingeschränkt möglich, weil hier die Reinigungswirkung der Spülmethoden im gesamten Wurzelkanal untersucht, während in der vorliegenden Studie die Sauberkeit des Isthmus bewertet wurde. Nach jetzigem Stand ist es in der endodontischen Therapie bisher nicht möglich, den Debris vollständig aus dem Isthmus zu entfernen. Die Frage, inwiefern im Endodont verbliebener Debris den Erfolg der Wurzelkanalbehandlung beeinträchtigt, kann zurzeit nicht beantwortet werden. Dies weist auf die Notwendigkeit hin, das chemo-mechanische Aufbereitungsprotokoll zu optimieren und somit die Ansammlung von Debris zu minimieren (De-Deus et al. 2014). 


\section{Zusammenfassung}

Ziel der Studie: Es wurde die Effektivität von schall- und ultraschallaktivierten Wurzelkanalspültechniken zur Entfernung von Debris aus dem Isthmus unterer Molaren mithilfe von Mikrocomputertomografie (Mikro-CT)-Analysen untersucht.

Material und Methode: Vierzig extrahierte Unterkiefer Molaren wurden anhand vergleichbarer anatomischer Parameter ausgewählt, die mesiale Wurzel abgetrennt und die Wurzelkanäle maschinell mit dem Reciproc R25-Instrument präpariert. Dabei wurde pro Wurzelkanal mit $8 \mathrm{ml} \mathrm{NaOCl}$ gespült. Der durch die Präparation entstandene Debris wurde durch Überlagerungen prä- und postoperativer Micro-CT-Scans berechnet. Unter Berücksichtigung des Debrisvolumens, des Wurzelkanalkrümmungswinkels und -radius, des Kanalvolumens und der Kanaloberfläche erfolgte die Einteilung der Zähne in vier homogene Gruppen. Anschließend wurden die Wurzelkanäle entsprechend ihrer Gruppeneinteilung gespült: 1. Handspülung, 2. Schallaktivierung durch EDDY, 3. Schallaktivierung durch EndoActivator, 4. Ultraschallaktivierung. Es wurden jeweils vier Aktivierungszyklen à $20 \mathrm{sec}$ durchgeführt. Bei der Handspülung wurde die Spülflüssigkeit entsprechend für $20 \mathrm{sec}$ im Wurzelkanal belassen. Zwischen den Aktivierungszyklen wurde mit insgesamt jeweils $5 \mathrm{ml}$ $\mathrm{NaOCl}$ und EDTA pro Wurzelkanal gespült. Im Anschluss erfolgte die Analyse des verbliebenen Debris mithilfe erneuter Mikro-CT-Scans. Die erhobenen Daten wurden abschließend statistisch ausgewertet.

Ergebnis: Es wurde kein signifikanter Unterschied in Bezug auf die Reduzierung des Debris aus dem Isthmus zwischen schall- und ultraschallaktivierter Spülung im Vergleich zur konventionellen Handspülung nachgewiesen.

Schlussfolgerung: Eine Schall- und Ultraschallaktivierung der Spülflüssigkeit verbesserte die Reinigungswirkung hinsichtlich der Debrisentfernung im Vergleich zur Handspülung nicht. In zukünftigen Studien sollten weitere Aktivierungsmethoden hinsichtlich einer möglichst vollständigen Beseitigung des Debris aus dem Wurzelkanalsystem überprüft werden. 


\section{Literaturverzeichnis}

Abou-Rass M, Piccinino MV (1982): The effectiveness of four clinical irrigation methods on the removal of root canal debris. Oral Surg Oral Med Oral Pathol 54, 323-328

Adcock JM, Sidow SJ, Looney SW, Liu Y, McNally K, Lindsey K, Tay FR (2011): Histologic evaluation of canal and isthmus debridement efficacies of two different irrigant delivery techniques in a closed system. J Endod 37, 544-548

Ahmad M, Pitt Ford TR, Crum LA (1987a): Ultrasonic debridement of root canals: an insight into the mechanisms involved. J Endod $\underline{13}, 93-101$

Ahmad M, Pitt Ford TR, Crum LA (1987b): Ultrasonic debridement of root canals: acoustic streaming and its possible role. J Endod 13, 490-499

Ahmad M, Pitt Ford TR, Crum LA, Walton AJ (1988): Ultrasonic debridement of root canals: acousitic cavitation and its relevance. J Endod 14, 486-493

Al-Jadaa A, Paqué F, Attin T, Zehnder M (2009): Acoustic hypochlorite activation in simulated curved canals. J Endod $\underline{25}, 1408-1411$

Albrecht L, Baumgartner J, Marshall J (2004): Evaluation of apical debris removal using various sizes and tapers of ProFile GT Files. J Endod $\underline{30}$, 425428

Amato M, Vanoni-Heineken I, Hecker H, Weiger R (2011): Curved versus straight root canals: the benefit of activated irrigation techniques on dentin debris removal. Oral Surg Oral Med Oral Pathol Oral Radiol Endod 111, 529534

Archer R, A R, Nist R, Beck M, J MW (1992): An in vivo ealuation of the efficacy of ultrasound after step-back preparation in mandibular molars. J Endod 18, 549-552

Arias-Moliz MT, Morago A, Ordinola-Zapata R, Ferrer-Luque CM, Ruiz-Linares $M$, Baca $P$ (2016): Effects of dentin debris on the antimicrobial properties of sodium hypochlorite and etidronic acid. J Endod $\underline{42}, 771-775$

Arslan H, Doganay E, Alsancak M, Capar ID, Karatas E, Gunduz HA (2016): Comparison of apically extruded debris after root canal instrumentation using Reciproc instruments with various kinematics. Int Endod J $\underline{49}$, 307-310

Barthel C, Georgi M, Schäfer E, Petschelt A, Flachsenberg S, Neuber T, Kockapan C, Weiger R, Hülsmann M: Wissenschaftliche Stellungnahme: Die 
Wurzelkanalspülung. DGZMK/DGZ 2006 [URL: https://www.dgzmk.de/ uploads/tx_szdgzmkdocuments/DGZMK_Stellungnahme_Wurzelkanalspuelung _10_2006.pdf] Zugriff 4.12.18

Baumann MA, Beer R (Hrsg.): Farbatlanten der Zahnmedizin: Endodontologie. 2. Auflage; Thieme, Stuttgart 2008

Baumgartner JC, Mader CL (1987): A scanning electron microscopic evaluation of four root canal irrigation regimens. J Endod $\underline{13}, 147-157$

Boutsioukis C, Gogos C, Verhaagen B, Versluis M, Kastrinakis E, Van der Sluis LW (2010): The effect of apical preparation size on irrigant flow in root canals evaluated using an unsteady computational fluid dynamics model. Int Endod $\mathrm{J}$ $\underline{43}, 874-881$

Boutsioukis C, Verhaagen B, Walmsley AD, Versluis M, van der Sluis LW (2013): Measurement and visualization of file-to-wall contact during ultrasonically activated irrigation in simulated canals. Int Endod J 46, 1046-1055

Brännström M, Johnson DDS (1974): Effects of various conditioners and cleaning agents on prepared dentin surfaces: a scanning electron microscopic investigation. J Prosthet Dent 31, 422-430

Bryce G, MacBeth N, Gulabivala K, Ng YL (2018): The efficacy of supplementary sonic irrigation using the EndoActivator system determined by removal of a collagen film from an ex vivo model. Int Endod J $\underline{51}, 489-497$

Çalt S, Serper A (2000): Smear layer removal by EGTA. J Endod $\underline{26}$, 459-461

Çalt S, Serper A (2002): Time-dependent effects of EDTA on dentin structures. J Endod $\underline{28}, 17-19$

Card SJ, Sigurdsson A, Orstavik D, Trope M (2002): The effectiveness of increased apical enlargement in reducing intracanal bacteria. J Endod $\underline{28}, 779-$ 783

Caron G, Nham K, Bronnec F, Machtou P (2010): Effectiveness of different final irrigant activation protocols on smear layer removal in curved canals. J Endod $\underline{36}, 1361-1366$

Carrotte $P$ (2004): Endodontics: Part 5 basic instruments and materials for root canal treatment. Br Dent J 197, 455-464

Conde AJ, Estevez R, Lorono G, Valencia de Pablo O, Rossi-Fedele G, Cisneros R (2017): Effect of sonic and ultrasonic activation on organic tissue dissolution from simulated grooves in root canals using sodium hypochlorite and EDTA. Int Endod J 므, 976-982 
Cury JA, Bragotto C, Valdrighi L (1981): The demineralizing efficiency of EDTA solutions on dentin. Oral Surg Oral Med Oral Pathol $\underline{52}$, 446-448

de Gregorio C, Estevez R, Cisneros R, Heilborn C, Cohenca N (2009): Effect of EDTA, sonic, and ultrasonic activation on the penetration of sodium hypochlorite into simulated lateral canals: an in vitro study. J Endod 35, 891-895

De-Deus G, Paciornik S, Mauricio MH (2006): Evaluation of the effect of EDTA, EDTAC and citric acid on the microhardness of root dentine. Int Endod J $\underline{39}$, 401-407

De-Deus G, Reis C, Beznos D, de Abranches AM, Coutinho-Filho T, Paciornik $S$ (2008): Limited ability of three commonly used thermoplasticized gutta-percha techniques in filling oval-shaped canals. J Endod $\underline{34}, 1401-1405$

De-Deus G, Reis C, Paciornik S (2011): Critical appraisal of published smear layer-removal studies: methodological issues. Oral Surg Oral Med Oral Pathol Oral Radiol Endod 112, 531-543

De-Deus G, Arruda TE, Souza EM, Neves A, Magalhaes K, Thuanne E, Fidel RA (2013): The ability of the Reciproc R25 instrument to reach the full root canal working length without a glide path. Int Endod J $\underline{46}$, 993-998

De-Deus G, Marins J, Neves Ade A, Reis C, Fidel S, Versiani MA, Alves H, Lopes RT, Paciornik S (2014): Assessing accumulated hard-tissue debris using micro-computed tomography and free software for image processing and analysis. J Endod $\underline{40}$, 271-276

Dutner J, Mines P, Anderson A (2012): Irrigation trends among american association of endodontists members: a web-based survey. J Endod $\underline{38}, 37-40$

Engelke K, Karolczak M, Lutz A, Seibert U, Schaller S, Kalender W (1999): Mikro-CT: Technologie und Applikationen zur Erfassung von Knochenarchitektur. Radiologie 39, 203-212

Falk KW, Sedgley CM (2005): The influence of preparation size on the mechanical efficacy of root canal irrigation In vitro. J Endod 31, 742-745

Freire LG, Iglecias EF, Cunha RS, dos Santos M, Gavini G (2015): Microcomputed tomographic evaluation of hard tissue debris removal after different irrigation methods and its influence on the filling of curved canals. J Endod $\underline{41}$, 1660-1666

Garberoglio R, Becce C (1994): Smear layer removal by root canal irrigants. Oral Surg Oral Med Oral Pathol $\underline{78}, 359-367$ 
Garg H, Grewal MS (2016): Cone-beam computed tomography volumetric analysis and comparison of dentin structure loss after retrieval of separated instrument by using ultrasonic EMS and ProUltra tips. J Endod 42, 1693-1698

Goldberg F, Spielberg C (1982): The effect of EDTAC and the variation of its working time analyzed with scanning electron microscopy. Oral Surg $\underline{53}, 74-77$

Goode N, Khan S, Eid AA, Niu LN, Gosier J, Susin LF, Pashley DH, Tay FR (2013): Wall shear stress effects of different endodontic irrigation techniques and systems. J Dent $\underline{41}, 636-641$

Gründling GL, Zechin JG, Jardim WM, de Oliveira SD, de Figueiredo JAP (2011): Effect of ultrasonics on enterococcus faecalis biofilm in a bovine tooth model. J Endod 37, 1128-1133

Gu L, Wei X, Ling J, Huang X (2009a): A microcomputed tomographic study of canal isthmuses in the mesial root of mandibular first molars in a Chinese population. J Endod $\underline{35}$, 353-356

Gu L, Kim JR, Ling J, Choi KK, Pashley DH, Tay FR (2009b): Review of contemporary irrigant agitation techniques and devices. J Endod $\underline{35}, 791-804$

Gutarts R, Nusstein J, Reader A, Beck M (2005): In vivo debridement efficacy of ultrasonic irrigation following hand-rotary instrumentation in human mandibular molars. J Endod 31, 166-170

Heidemann D, Hülsmann M, Petschelt A, Raab WHM, Schäfer E, Weiger R: Wissenschaftliche Stellungsnahme: Die maschinelle Wurzelkanalaufbereitung. DGZMK/DGZ 2005 [URL: https://www.dgzmk.de/uploads/tx_szdgzmk documents/Die_maschinelle_Wurzelkanalaufbereitung.pdf] Zugriff 4.12.18

Hülsmann M, Rümmelin C, Schäfers F (1997): Root canal cleanliness after preparation with different endodontic handpieces and hand instruments: a comparative SEM investigation. J Endod 23, 301-306

Hülsmann M, Heckendorff M, Lennon A (2003): Chelating agents in root canal treatment: mode of action and indications for their use. Int Endod J $\underline{36}, 810-830$

Hülsmann M, Peters OA, Dummer P (2005): Mechanical preparation of root canals: shaping goals, technique and means. Endod Topics $\underline{10}$, 30-76

ISO (Internationale Organisation für Normung) (2008): ISO 3630-1:2008 Dentistry--Root-canal instruments-- Part 1: General requirements and test methods [URL: https://www.iso.org/standard/37702.html] Zugriff 14.12.18 
Jeon HJ, Paranjpe A, Ha JH, Kim E, Lee W, Kim HC (2014): Apical enlargement according to different pecking times at working length using reciprocating files. J Endod $\underline{40}, 281-284$

Jiang LM, Verhaagen B, Versluis M, van der Sluis LW (2010): Evaluation of a sonic device designed to activate irrigant in the root canal. J Endod 36, 143-146 Jiang LM, Verhaagen B, Versluis M, Langedijk J, Wesselink P, van der Sluis LW (2011): The influence of the ultrasonic intensity on the cleaning efficacy of passive ultrasonic irrigation. J Endod $\underline{37}$, 688-692

Jiang LM, Lak B, Eijsvogels LM, Wesselink P, van der Sluis LW (2012): Comparison of the cleaning efficacy of different final irrigation techniques. $J$ Endod $\underline{38}, 838-841$

Jimna M, Ashwini T, Sowmya H (2017): Comparison and evaluation of two reciprocating root canal instruments on removal of smear layer by using two irrigants at apical one-third of the root canal- an ex vivo-scanning electron microscopic study. J Conserv Dent 20, 451-458

Jirik M, Bartos M, Tomásek P, Malecková A, Kural T, Horáková J, Lukás D, Suchy T, Kochová P, Kalbácová M, et al. (2018): Generating standardized image data for testing and calibrating quantification of volumes, surfaces, lengths, and object counts in fibrous and porous materials using X-ray microtomography. Microsc Res Tech $\underline{81}, 100-112$

Jung M, Lommel D, Klimek J (2005): The imaging of root canal obturation using micro-ct. Int Endod J $\underline{38}, 617-626$

Kahn FH, Rosenberg PA, Gliksberg J (1995): An In vitro evaluation of the irrigating characteristics of ultrasonic and subsonic handpieces and irrigating needles and probes. J Endod 21, 277-280

Keleş A, Alçin H, Sousa-Neto MD, Versiani MA (2016): Supplementary steps for removing hard tissue debris from isthmus-containing canal systems. $J$ Endod $\underline{42}, 1677-1682$

Kiefner P (2015): Wurzelkanalaufbereitung mit reziproker Technik. Dentalzeitung $\underline{15}, 19-23$

Klyn SL, Kirkpatrick TC, Rutledge RE (2010): In vitro comparisons of debris removal of the EndoActivator system, the $\mathrm{F}$ file, ultrasonic irrigation, and $\mathrm{NaOCl}$ irrigation alone after hand-rotary instrumentation in human mandibular molars. $\mathrm{J}$ Endod $\underline{36}, 1367-1371$

Lacerda M, Marceliano-Alves MF, Perez AR, Provenzano JC, Neves MAS, Pires FR, Goncalves LS, Rocas IN, Siqueira JF (2017): Cleaning and shaping 
oval canals with 3 instrumentation systems: a correlative micro-computed tomographic and histologic study. J Endod $\underline{43}, 1878-1884$

Lambrianidis T (2009): Ledging and blockage of root canals during canal preparation: causes, recognition, prevention, management, and outcomes. Endod Topics 15, 56-74

Larsen T, Fiehn NE (2017): Dental biofilm infections - an update. APMIS $\underline{125}$, 376-384

Lee SJ, Wu MK, Wesselink PR (2004a): The efficacy of ultrasonic irrigation to remove artificially placed dentine debris from different- sized simulated plastic root canals. Int Endod J 37, 607-612

Lee SJ, Wu MK, Wesselink PR (2004b): The effectiveness of syringe irrigation and ultrasonics to remove debris from simulated irregularities within prepared root canal walls. Int Endod J $\underline{37}, 672-678$

Leoni GB, Versiani MA, Silva-Sousa YT, Bruniera JF, Pecora JD, Sousa-Neto MD (2016): Ex vivo evaluation of four final irrigation protocols on the removal of hard-tissue debris from the mesial root canal system of mandibular first molars. Int Endod J 무, 398-406

Lloyd A, Uhles JP, Clement DJ, Garcia-Godoy F (2014): Elimination of intracanal tissue and debris through a novel laser-activated system assessed using high-resolution micro-computed tomography: a pilot study. J Endod $\underline{40}$, 584-587

Mader CL, Baumgartner JC, Peters DD (1984): Scanning electron microscopic investigation of the smeared layer on root canal walls. J Endod $\underline{10}, 477-483$

Malki M, Verhaagen B, Jiang LM, Nehme W, Naaman A, Versluis M, Wesselink $P$, van der Sluis L (2012): Irrigant flow beyond the insertion depth of an ultrasonically oscillating file in straight and curved root canals: visualization and cleaning efficacy. J Endod $\underline{38}, 657-661$

McComb D, Smith DC (1975): A preliminary scanning electron microscopi study of root canals after endodontic procedures. J Endod 1, 238-242

Mozo S, Llena C, Forner L (2012): Review of ultrasonic irrigation in endodontics: increasing action of irrigating solutions. Med Oral Patol Oral Cir Bucal 17, 512-516

Nair PN, Henry S, Cano V, Vera J (2005): Microbial status of apical root canal system of human mandibular first molars with primary apical periodontitis after "one-visit" endodontic treatment. Oral Surg Oral Med Oral Pathol Oral Radiol Endod 99, 231-252 
Neboda C, Anthonappa RP, King NM (2018): Preliminary investigation of the variations in root canal morphology of hypomineralised second primary molars. Int J Paediatr Dent 28, 310-318

Nielsen RB, Alyassin AM, Peters DD, Carnes DL, Lancaster J (1995): Microcomputed tomography: an advanced system for detailed endodontic research. J Endod 21, 561-568

Nygaard-Østby B (1957): Chelation in root canal therapy. Odontol Tidskr $\underline{65}$, 311

Özdemir HO, Buzoglu HD, Calt S, Stabholz A, Steinberg D (2010): Effect of ethylenediaminetetraacetic acid and Sodium Hypochlorite irrigation on enterococcus faecalis biofilm colonization in young and old human root canal dentin: in vitro study. J Endod $\underline{36}, 842-846$

Paqué F, Musch U, Hülsmann M (2005): Comparison of root canal preparation using $\mathrm{RaCe}$ and ProTaper rotary Ni-Ti instruments. Int Endod J $\underline{38}, 8-16$

Paqué F, Laib A, Gautschi H, Zehnder M (2009a): Hard-tissue debris accumulation analysis by high-resolution computed tomography scans. J Endod 35, 1044-1047

Paqué F, Ganahl D, Peters OA (2009b): Effects of root canal preparation on apical geometry assessed by micro-computed tomography. J Endod 35, 10561059

Paqué F, Boessler C, Zehnder M (2011): Accumulated hard tissue debris levels in mesial roots of mandibular molars after sequential irrigation steps. Int Endod $\mathrm{J} \underline{44}, 148-153$

Paqué F, Al-Jadaa A, Kfir A (2012): Hard-tissue debris accumulation created by conventional rotary versus self-adjusting file instrumentation in mesial root canal systems of mandibular molars. Int Endod J $\underline{45}, 413-418$

Paragliola R, Franco V, Fabiani C, Mazzoni A, Nato F, Tay FR, Breschi L, Grandini S (2010): Final rinse optimization: influence of different agitation protocols. J Endod $\underline{36}, 282-285$

Perez AR, Alves FRF, Marceliano-Alves MF, Provenzano JC, Goncalves LS, Neves AA, Siqueira JF (2018): Effects of increased apical enlargement on the amount of unprepared areas and coronal dentine removal: a micro-computed tomography study. Int Endod J 51, 684-690

Perez R, Neves AA, Belladonna FG, Silva E, Souza EM, Fidel S, Versiani MA, Lima I, Carvalho C, De-Deus G (2016): Impact of needle insertion depth on the removal of hard-tissue debris. Int Endod J $\underline{50}, 560-568$ 
Peters OA, Laib A, Gohring TN, Barbakow F (2001): Changes in root canal geometry after preparation assessed by high-resolution computed tomography. J Endod 27, 1-6

Pitt W (2005): Removal of oral biofilm by sonic phenomena. Am J Dent 18, 345352

Plotino G, Cortese T, Grande N, Leonardi D, Di Giorgio G, Testarelli L, Gambarini G (2016): New technologies to improve root canal disinfection. Braz Dent J $\underline{27}, 3-8$

Queiroz PM, Rovaris K, Gaeta-Araujo H, Marzola de Souza Bueno S, Freitas DQ, Groppo FC, Haiter-Neto F (2017a): Influence of artifact reduction tools in micro-computed tomography images for endodontic research. J Endod $\underline{43}$, 2108-2111

Queiroz PM, Rovaris K, Santaella GM, Haiter-Neto F, Freitas DQ (2017b): Comparison of automatic and visual methods used for image segmentation in endodontics: a microCT study. J Appl Oral Sci $\underline{25}$, 674-679

Ram Z (1977): Effectiveness of root canal irrigation. Oral Surg Oral Med Oral Pathol $\underline{44}$, 306-312

Retsas A, Koursoumis A, Tzimpoulas N, Boutsioukis C (2016): Uncontrolled removal of dentin during in vitro ultrasonic irrigant activation in curved root canals. J Endod $\underline{42}, 1545-1549$

Richman MJ (1957): The use of ultrasonics in root canal therapy and root resection. J Med 12, 12-18

Robinson JP, Lumley PJ, Claridge E, Cooper PR, Grover LM, Williams RL, Walmsley AD (2012): An analytical micro ct methodology for quantifying inorganic dentine debris following internal tooth preparation. J Dent $\underline{40}, 999-$ 1005

Rödig T, Hülsmann M, Nordmeyer S, Drebenstedt S: Grundlagen der moderenen Endodontie. Spitta Verlag, Balingen 2009

Rödig T, Dollmann S, Konietschke F, Drebenstedt S, Hulsmann M (2010): Effectiveness of different irrigant agitation techniques on debris and smear layer removal in curved root canals: a scanning electron microscopy study. J Endod 36, 1983-1987

Roy R, Ahmad M, Crum LA (1994): Physical mechanisms governing the hydrodynamic response of an oscillating ultrasonic file. Int Endod J 27, 197-207 
Ruatala WA, Weber DJ (1997): Uses of inorganic hypochlorite (bleach) in health-care facilities. Clin Microbiol Rev $\underline{10}$, 597-610

Sabins RA, Johnson JD, Hellstein JW (2003): A comparison of the cleaning efficacy of short-term sonic and ultrasonic passive irrigation after hand instrumentation in molar root canals. J Endod 29, $674-678$

SBU: Methods of diagnosis and treatment in endodontics. Swedish Council on Health Technology Assessment (SBU). Stockholm 2010 (english version in 2012); [URL: https://www.sbu.se/en/publications/sbu-assesses/methods-ofdiagnosis-and-treatment-in-endodontics/] Zugriff 24.4.18

Scelza MrFZ, Pierro V, Scelza P, Pereira M (2004): Effect of three different time periods of irrigation with EDTA-T, EDTA, and citric acid on smear layer removal.

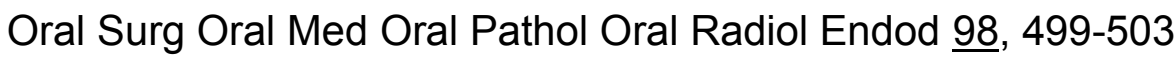

Schäfer E, Hickel R, Geurtsen W, Heidemann D, Löst C, Petschelt A, Raab W: Wissenschaftliche Stellungnahme: Wurzelkanalaufbereitungen. DGZMK/DGZ 2000 [URL: https://www.dgzmk.de/uploads/tx_szdgzmkdocuments/Wurzelkanal aufbereitungen.pdf] Zugriff 4.12.18

Schäfer E, Lohmann D (2002): Efficiency of rotary nickel-titanium FlexMaster instruments compared with stainless steel hand K-Flexofile--Part 1. Shaping ability in simulated curved canals. Int Endod J $\underline{35}, 505-513$

Schäfer E, Diez C, Hoppe W, Tepel J (2002): Roentgenographic investigation of frequency and degree of canal curvatures in human permanent teeth. $\mathrm{J}$ Endod $\underline{28}, 211-216$

Schiavotelo TCL, Coelho MS, Rasquin LC, Rocha DGP, Fontana CE, Bueno C (2017): Ex-vivo smear layer removal efficacy of two activated irrigation techniques after reciprocating instrumentation in curved canals. Open Dent $J$ $\underline{11}, 512-519$

Schneider SW (1971): A comparison of canal preparations in straight and curved root canals. Oral Surg Oral Med Oral Pathol $\underline{32}$, 271-275

Shahravan A, Haghdoost AA, Adl A, Rahimi H, Shadifar F (2007): Effect of smear layer on sealing ability of canal obturation: a systematic review and meta-analysis. J Endod $\underline{33}, 96-105$

Silva E, Carvalho CR, Belladonna FG, Prado MC, Lopes RT, De-Deus G, Moreira EJL (2019): Micro-CT evaluation of different final irrigation protocols on the removal of hard-tissue debris from isthmus-containing mesial root of mandibular molars. Clin Oral Investig $\underline{23}, 681-687$ 
Siqueira JF (2005): Reaction of periradicular tissues to root canal treatment: benefits and drawbacks. Endod Topics 10, 123-147

Siqueira JF, Rocas IN, Favieri A, Lima KC (2000): Chemomechanical reduction of the bacterial population in the root canal after instrumentation and irrigation with $1 \%, 2.5 \%$, and $5.25 \%$ sodium hypochlorite. J Endod $\underline{26}$, 331-334

Siqueira JF, Alves FR, Almeida BM, de Oliveira JC, Rocas IN (2010): Ability of chemomechanical preparation with either rotary instruments or self-adjusting file to disinfect oval-shaped root canals. J Endod $\underline{36}, 1860-1865$

Siqueira JF, Alves FRF, Versiani MA, Rôças IN, Almeida BM, Neves MAS, Sousa-Neto MD (2013): Correlative bacteriologic and micro-computed tomographic analysis of mandibular molar mesial canals prepared by SelfAdjusting File, Reciproc, and twisted file systems. J Endod 39, 1044-1050

Susin L, Liu Y, Yoon JC, Parente JM, Loushine RJ, Ricucci D, Bryan T, Weller RN, Pashley DH, Tay FR (2010): Canal and isthmus debridement efficacies of two irrigant agitation techniques in a closed system. Int Endod J $\underline{43}, 1077-1090$

Swimberghe RCD, De Clercq A, De Moor RJG, Meire MA (2019): Efficacy of sonically, ultrasonically and laser- activated irrigation in removing a biofilmmimicking hydrogel from an isthmus model. Int Endod J $\underline{52}, 515-523$

Taschieri S, Del Fabbro M, Samaranayake L, Chang JWW, Corbella S (2014): Microbial invasion of dentinal tubules: a literature review and a new perspective. J Investig Clin Dent $\underline{5}, 163-170$

Taylor JK, Jeansonne BG, Lemon RR (1997): Coronal leakage: effects of smear layer, obturation technique, and sealer. J Endod 23, 508-512

Tennert C (2013): Die Desinfektion des Wurzelkanalsystems. Dtsch Zahnärztl Z $\underline{68}, 696-706$

Tepel J, Schäfer E, Hoppe W (1995): Root canal instruments for manual use: cutting efficience and instrumentation of curved canals. Int Endod J 28, 68-76

Tronstad L, Barnett F, Schwartzben L, Frasca P (1985): Effectiveness and safety of a sonic vibratory endodontic instrument. Endod Dent Traumatol 1, 6976

Urban K, Donnermeyer D, Schäfer E, Burklein S (2017): Canal cleanliness using different irrigation activation systems: a SEM evaluation. Clin Oral Invest $\underline{21}, 2681-2687$

van der Sluis LW, Gambarini G, Wu MK, Wesselink PR (2006): The influence of volume, type of irrigant and flushing method on removing artificially placed 
dentine debris from the apical root canal during passive ultrasonic irrigation. Int Endod J 39, 472-476

van der Sluis LW, Versluis M, Wu MK, Wesselink PR (2007): Passive ultrasonic irrigation of the root canal: a review of the literature. Int Endod J $\underline{40}, 415-426$

van der Sluis LW, Wu MK (2009): Comparison of 2 flushing methods used during passive ultrasonic irrigation of the root canal. Quintessence Int $\underline{40}$, 857859

VDW (2017): EDDY Innovative Sonic Powered Irrigation [URL:https://www.vdwdental.com/fileadmin/Dokumente/Sortiment/Spuelung/Eddy/VDW-DentalEDDY-product-brochure-DE.pdf] Zugriff 01.05.18

Verma P, Love RM (2011): A micro ct study of the mesiobuccal root canal morphology of the maxillary first molar tooth. Int Endod J $\underline{44}, 210-217$

Versiani MA, Leoni GB, Steier L, De-Deus G, Tassani S, Pecora JD, de SousaNeto MD (2013): Micro-computed tomography study of oval-shaped canals prepared with the self-adjusting file, Reciproc, WaveOne, and ProTaper universal systems. J Endod 39, 1060-1066

Versiani MA, Alves FR, Andrade-Junior CV, Marceliano-Alves MF, Provenzano JC, Rocas IN, Sousa-Neto MD, Siqueira JF (2016): Micro-CT evaluation of the efficacy of hard-tissue removal from the root canal and isthmus area by positive and negative pressure irrigation systems. Int Endod J 499, 1079-1087

Verstraeten J, Jacquet W, De Moor RJG, Meire MA (2017): Hard tissue debris removal from the mesial root canal system of mandibular molars with ultrasonically and laser-activated irrigation: a micro-computed tomography study. Laser Med Sci 32, 1965-1970

Vertucci FJ (1984): Root canal anatomy of the human permanent teeth. Oral Surg Oral Med Oral Pathol $\underline{58}, 589-599$

Violich DR, Chandler NP (2010): The smear layer in endodontics - a review. Int Endod J $\underline{43}, 2-15$

Virdee SS, Seymour DW, Farnell D, Bhamra G, Bhakta S (2018): Efficacy of irrigant activation techniques in removing intracanal smear layer and debris from mature permanent teeth: a systematic review and meta-analysis. Int Endod J 1ㅜ, 605-621

Vivan RR, Duque JA, Alcalde MP, So MV, Bramante CM, Duarte MA (2016): Evaluation of different passive ultrasonic irrigation protocols on the removal of dentinal debris from artificial grooves. Braz Dent J $\underline{27}, 568-572$ 
White RR, Goldman M, Lin PS (1984): The influence of the smeared layer upon dentinal tubule penetration by plastic filling materials. J Endod 10, 558-562

Wu MK, Wesselink PR (2001): A primary observation on the preparation and obturation of oval canals. Int Endod J $\underline{34}, 137-141$

Yamada RS, Armas A, Goldman M, Lin PS (1983): A scanning electron microscopic comparison of a high volume final flush with several irrigating solutions: part 3. J Endod $\underline{9}$, 137-142

Zeeck A, Eick S, Krone B, Schröder K: Chemie für Mediziner. 2. Auflage; Urban \& Schwarzenberg, München 1992

Zehnder M (2006): Root canal irrigants. J Endod 32, 389-398 


\section{$9 \quad$ Anhang}

\subsection{Materialliste}

\begin{tabular}{|c|c|}
\hline Bruker Micro-CT Skyscan 1272 & Bruker, Billerica, Massachusetts, USA \\
\hline CTAnalyzer & Bruker, Billerica, Massachusetts, USA \\
\hline CTVox & Bruker, Billerica, Massachusetts, USA \\
\hline DataViewer & Bruker, Billerica, Massachusetts, USA \\
\hline Diamantbohrer & Gebr. Brasseler GmbH \& Co. KG, Lemgo \\
\hline EDDY & VDW GmbH, München \\
\hline Einwegspritze & B.Braun AG, Melsungen \\
\hline Endo Eze Tip & Ultradent, South Jordan, Utah, USA \\
\hline EndoActivator & Dentsply Sirona, York, Pennsylvania, USA \\
\hline Ethylendiamintetraessigsäure $15 \%$ & lege artis Pharma GmbH \& Co. KG, Dettenhausen \\
\hline Excel & Microsoft, Redmond, Washington, USA \\
\hline ImageJ & $\begin{array}{l}\text { National Institutes of Health, Bethesda, Maryland, } \\
\text { USA }\end{array}$ \\
\hline IRRI S & VDW GmbH, München \\
\hline Komposit & Heraeus Kulzer, Hanau \\
\hline Lindemannfräse & Gebr. Brasseler GmbH \& Co. KG, Lemgo \\
\hline Natriumhypochlorid $1 \%$ & Hedinger GmbH \& Co. KG, Stuttgart \\
\hline NRecon & Bruker, Billerica, Massachusetts, USA \\
\hline Optibond FL & Kerr GmbH, Biberach \\
\hline Papierspitzen ISO-Größe 15 & Roeko, Langenau \\
\hline Reamer ISO-Größe 10 & VDW GmbH, München \\
\hline Reciproc R25 & VDW GmbH, München \\
\hline
\end{tabular}


Scaler

Sonic

Statistica

VDW Silver Motor
Hu-Friedy, Chicago, Illinois, USA

KaVo, Biberach/Riß

StatSoft GmbH, Hamburg

VDW GmbH, München 


\section{Danksagung}

Hiermit möchte ich mich bei Frau PD. Dr. med. dent. Tina Rödig aus der Poliklinik für Präventive Zahnmedizin, Parodontologie und Kariologie des Zentrums Zahn-Mund-Kieferheilkunde der Universitätsmedizin Göttingen für die engagierte Betreuung sowohl während der Planung und Durchführung als auch bei der Korrektur meiner Dissertation bedanken.

Des Weiteren gilt mein Dank Frau Dr. Marta Rizk für die begleitende Betreuung und Erklärung am Mikro-CT sowie die schnelle Fehlerbehebung.

Bei Mareen Schäfers möchte ich mich für die unbeschwerte gemeinsame Studienzeit bedanken, die mich dazu angespornt hat, den größten Teil der Dissertation schon während des Studiums zu bewältig 